\title{
Delaying the normal and early retirement ages in Spain: behavioural and welfare consequences for employed and unemployed workers *
}

\author{
Alfonso R. Sánchez ${ }^{\dagger}$ \\ J. Ignacio García-Pérez $\ddagger$ \\ Sergi Jiménez-Martín ${ }^{\S}$
}

May 31, 2014

\begin{abstract}
In this paper, we explore the links between pension reform, early retirement, and the use of unemployment as an alternative pathway to retirement. We use a dynamic rational expectations model to analyze the search and retirement behaviour of employed and unemployed workers aged 50 or over. The model is calibrated to reproduce the main reemployment and retirement patterns observed between 2002 and 2008 in Spain. It is subsequently used to analyze the effects of the 2011 pension reform in Spain, characterized by two-year delays in both the early and the normal retirement ages. We find that this reform generates large increases in labour supply and sizable cuts in pension costs, but these are achieved at the expense of very large welfare losses, especially among unemployed workers. As an alternative, we propose leaving the early retirement age unchanged, but penalizing the minimum pension (reducing its generosity in parallel to the cuts imposed on individual pension benefits, and making it more actuarially fair with age). This alternative reform strikes a better balance between individual welfare and labour supply stimulus.
\end{abstract}

\footnotetext{
${ }^{*}$ We are grateful for the support from the Spanish Social Security through FIPROS 2007 and projects ECO201130323-C03-02 and SEJ2006-04803/ECON. Our thanks to the audience at the conferences ESPE 2013 (Aarhus) and 'The labour market for older workers: Mechanisms and Institutions" (CPB, The Hague). The usual disclaimer applies.

${ }^{\dagger}$ Universidad Pablo de Olavide

${ }^{\ddagger}$ Universidad Pablo de Olavide. Department of Economics, Crta. Utrera Km 1, 41013 Seville (Spain), jigarper@upo.es

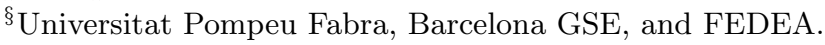




\section{Introduction}

The impact of population ageing on the financing of social security systems has received considerable attention in the last twenty years. The continuous process of demographic change implies an increase in the proportion of retirees with respect to the working population, which poses an important threat to the financial sustainability of social security around the world. Greater longevity, together with the strong tendency to bring forward retirement, especially until the mid 1990s, has led to a substantial increase in the number of years spent in retirement (which has practically doubled in the last 25 years in many OECD countries, see Wise (2011)). As these increases are associated with longer life spans (see, again, Wise (2011)), more and more calls have been made for an increase in both the retirement age and the labour force participation of older workers.

There is widespread unanimity today, in both the academic and political arenas, favouring a stronger link between senior workers and the labour market, and demanding a stop or reversal of the tendency towards early retirement among the former. A good example of this general attitude is the objective stated at the 2000 EU Lisbon Summit and reiterated recently in the Europe 2020 strategy of achieving a global employment rate of $50 \%$ for workers aged 50 to 69 . In practice, a large number of pension reforms have been implemented in recent years throughout the majority of developed countries (see OECD (2013)). The common denominator in these reforms involves a delay in both the early and the normal retirement age. Spain's 2011 reform is a good example of this trend, featuring two-year delays in those ages (63 and 67, respectively), and an increase in the number of years of contribution required to receive full benefits. ${ }^{1}$

The results from these reforms are, however, uncertain, depending on a number of interconnected factors. Most public debate, and a majority of the original academic research (from the 1970s to the 90s), focused on the transition from employment to retirement in systems where there is a Normal Retirement Age (NRA) and an Early Retirement Age (ERA). ${ }^{2}$ This literature emphasizes how pension rules penalize the extension of working lives, by imposing an implicit tax on the labour participation of senior workers. There has been a lot of work on how the formulas behind the computation of pensions, the existence of minimum and maximum pensions, contributory caps and ceilings, etc. result in such an implicit tax. When combined with borrowing constraints, these mechanisms lead to widespread early retirement. These facts have been studied using an ample spectrum of applied methodologies, ranging from the (relatively simple) computation of implicit monetary incentives (see Gruber and Wise, 1999, 2004 and 2007), to complex econometric analyses (both structural and reduced-form) and calibrated simulations of life-cycle behaviour. ${ }^{3}$

\footnotetext{
${ }^{1}$ See de la Fuente and Doménech (2012) for a complete description of the reform.

${ }^{2}$ At the Normal Retirement Age, workers who have contributed in full during their working lives enjoy full pension benefits. However, workers are usually allowed to collect penalized benefits at earlier ages, starting at the Early Retirement Age.

${ }^{3}$ Regarding the literature on reduced-form econometric analysis, see Samwick (1998), and for the Spanish case, Jiménez-Martín and Sánchez-Martín (2004), Boldrin et al. (2004), or, more recently, Cairó (2010) and García-Pérez et al. (2013); while Jiménez-Martín and Sánchez-Martín (2007), or the classic works by Rust and Phelan (1997) or French (2005), or Van der Klaauw and Wolpin (2008), as good examples of the use of structural econometrics.
} 
The challenges posed by early retirement have also been explored in more theoretical models, invoking both normative and positive considerations. The usual starting point is the first best outcome in an undistorted setting: for an individual, the best time to retire is when the marginal disutility of work is equal to his/her marginal productivity at work. As a consequence, we should expect people with low productivity and/or health issues to retire earlier than people with higher levels in either of those dimensions. A diversity of retirement ages (or at least, a sizable separation between the ERA and the NRA) may simply reflect the underlying diversity of workers within an economy. Of course, there are other factors at work in the real world. First and foremost, redistributive governments found that subsidizing early pensions was a natural policy tool for fighting poverty. ${ }^{4}$ Unfortunately, asymmetric information creates a classical moral hazard problem in this provision: the subsidized early pensions intended for disadvantaged workers can be claimed by perfectly healthy (but otherwise indistinguishable) workers. Early retirement has also been seen as discouraging investment in human capital and contributing to the poverty of the survivors of the household head. ${ }^{5}$ Eventually, a shrinking labour supply and, especially, the budgetary costs of early retirement have lead to the general political consensus mentioned above, favouring an aggressive limitation of early retirement options.

This consensus may, however, be misguided, as there are numerous reasons favouring at least some limited early retirement options. The ideal outcome (as argued in Cremer et al. (2004)) would be to let early retirees with poor health receive relatively generous benefits, while early retirees unwilling to continue working receive actuarially low pensions. Furthermore, Pestieau and Lozachmeur (2008) show that at least some distortions can be justified when public authorities use social insurance for redistribution, and only distortionary tax tools are available. In practical terms, we side with Cremer and Pestieau (2003) in advocating the maintenance of the ERA option as part of the pension reforms delaying the NRA. That will be our main policy suggestion in this paper.

Furthermore, statutory early retirement is only part of the story. Research over the past few years has progressively unearthed the complex reality of alternative pathways out of the labour force. Dorn and Sousa-Poza (2010) is a comparative study of the numerous alternatives available. They include, in particular, disability pensions (see, for example, Benitez-Silva et al. (1999) or Rust et al. (2002) for the United States and Borsch-Supan (2000), Jiménez-Martín et al. (2006) and Lammers et al. (2010) for the European case) and unemployment benefits (see Kyyrä and Ollikainen (2009), Giesecke and Kind (2013) or García Pérez and Sánchez Martín (2013)). We focus here on unemployment, which is a popular exit route in Spain (see eg, García-Pérez et al. (2013)), as it is, too, in other European countries (see below). Current pension systems can be easily manipulated, inducing the voluntary use of unemployment as a way to reduce penalties associated with early retirement. ${ }^{6}$ As described in García Pérez and Sánchez Martín (2013), senior workers can remain only nominally "active", collecting unemployment benefits without incurring in any search effort. This behaviour has a potentially serious downside for pension

\footnotetext{
${ }^{4}$ Also to make room for the young, under the "lump of labour fallacy", as discussed in, for example, Munnnell and Yanyuan Wu (2012), pages 136-137.

${ }^{5}$ See, for example, Manuelli et al. (2012)).

${ }^{6}$ We focus on the voluntary component of early retirement, but real world decisions are far from being purely "voluntary" (see Dorn and Sousa-Poza (2010) for Europe and Hutchens (1999) for the US).
} 
reform: a worker may ignore a potential job offer that would mean a return to paid employment or even decide not to retire in order to elude early retirement penalties. Both decisions may lead to an increase in the financial liabilities of the combined pension and unemployment benefit system. They may, at least partially, offset both the expected (positive) labour supply effects, as well as the budgetary impact of these reforms.

Several recent papers have documented how employed and unemployed workers' decisions about retirement are affected by changes in early retirement programmes. For example, according to Vestad (2013), a reduction in the age limit for early retirement in Norway has made many more workers decide to stop working after this reform was passed. Furthermore, Staubli and Zweimüller (2013) documents the fact that moving in the opposite direction, that is, raising the Early Retirement Age (ERA), as has been the case in Austria between 2001 and 2010, has increased employment between 10 and 11 points among affected workers. Yet these changes in the ERA have some added consequences on unemployment and/or disability insurance systems. That paper also shows that unemployment increased in Norway by around $12 \%$ among workers aged 52-59 after that reform was implemented. Hence, it seems that the unemployment insurance (UI) system may serve as a "bridge" to retirement benefits, at least for some workers with poor employment prospects. Nevertheless, there may also be some other behavioural responses to a higher ERA. As Giesecke and Kind (2013) documents for Germany, increasing the ERA from 60 to 63 makes prolonged unemployment less attractive, creating new incentives for unemployed workers to return to work due to distance-to-retirement issues (in line with the theoretical arguments developed by Hairault et al. (2010)). However, we have to take into account that not all unemployed workers might have the same opportunities to return to work. As found by Staubli and Zweimüller (2013), only high-wage and healthy workers can be re-employed after reactivating their search activities. Less healthy workers, or those with poor perspectives in the labour market, have to remain unemployed, which exposes them to higher penalties in terms of future pension benefits when the ERA is postponed. These studies are linked to the more general discussion of how to make unemployed workers search more. ${ }^{7}$

All in all, it is clear that the complex interplay between unemployment and early retirement rules demands additional and specific analysis. In this paper, we aim to contribute to that research effort. We continue the development of the structural search model in García Pérez and Sánchez Martín (2013). It captures the uncertainties present in job seeking, the alternative of voluntary non-participation to avoid penalized early retirement, and other complex interactions with retirement regulation. Employees may participate in voluntary retirement and are linked to unemployment via an exogenous firing risk (although we also explore their incentives for voluntary unemployment). The model is calibrated on a stylized version of the Spanish pension system, using data from the Spanish Social Security Registers. ${ }^{8}$

\footnotetext{
${ }^{7}$ Both Lammers et al. (2010), for the Netherlands, and Kyyrä and Ollikainen (2009), for Finland, analyze whether or not it is best for older workers to search when unemployed. Lammers et al. (2010) finds that an increase in the search requirements for older unemployed workers significantly increases workers' entry into employment. However, practically no substitution is found between UI benefits and early retirement benefits. This is because penalties on early retirement were increased in the Netherlands at the same time.

${ }^{8}$ This administrative dataset includes information on the complete labour histories of more than one million Spanish workers. We focus here on a relatively narrow sub-sample of 21,902 male workers selected to guarantee that
} 
We then apply the model to two policy experiments. First, we explore a delay in the key legal ages of the pension system, 60 and 65, to 63 and 67 years, respectively. We evaluate the consequences on labour supply, on the expected cost for the overall public insurance system (pension and unemployment benefits), and on the individual welfare for both employed and unemployed workers. We find that employed workers react to the new incentives introduced by the reform with a widespread postponing of voluntary retirement. The unemployed resort to voluntary non-participation in much lower numbers than under the current arrangement. In fact, the reform renders the previously prevailing tendency to take refuge in unemployment before the ERA/NRA much less convenient. By contrast, our model predicts a surge in the search effort of the unemployed. The financial consequences of the reform are also very satisfactory. We identify a significant cost-saving among employees, which is not a surprise, but we also find that the savings involving the unemployed are even higher. But this picture can be dismissed when welfare losses are precisely quantified. Pension reform is damaging for employees, but its impact on the unemployed is truly devastating, with losses more than doubling the savings achieved in term of costs. In response to these findings (and in light of the literature reviewed above), we consider a second experiment in which the Early Retirement Age is left unchanged, but we penalize the value of minimum pensions to increase their actuarial fairness. This second environment strikes a better balance between labour/financial gains and welfare costs.

The structure of the rest of the paper is as follows: in section 2 we revise the formal features of our model and describe in detail its calibration to the Spanish case. The findings in our simulation experiments are discussed at length in section 3. Our conclusions from the experiments are presented in section 4 , and a few technical appendices are attached to conclude the paper.

\section{Model and its calibration}

\subsection{The model of individual behaviour}

We model a labour market whose intrinsic dynamics results from the interaction of individual choices and random shocks. Our decision-makers are individuals aged 55/70 that can be either employed or unemployed. Individuals can also be retired, which implies pension collection and a permanent withdrawal from the labour force. Our active individuals are heterogeneous in several dimensions: employees differ in their current wage, $w$, and in their accumulated pension rights, $\hat{w}$ (defined below), while unemployed workers have different previous wages $\pi$ (salaries in the immediately preceding employment spell), accrued pension rights, and lengths of their unemployment spells, $h$ (grouped into three discrete categories: less than one year, between one and two years, and more than two years). These are the state variables in our recursive representation of the dynamic problem faced by the agents.

Individual choices depend on age. On or after the Early Retirement Age (ERA), employees

the economic incentives of individuals are clearly identified. These workers are all affiliated to the General Regime of the Spanish Social Security System, and are also entitled to receive contributory unemployment benefits and pensions upon retirement. We have all their employment and unemployment spells during the 2002-2008 period. A complete description of the database, along with a detailed reduced-form econometric analysis can be found in García-Pérez et al. (2013)). 
can stop working, claim their individual pension and retire. They could also be made redundant by their employers at any age, forcing them to continue their participation in the labour market as newly unemployed workers. Firing is an exogenous mechanism in our simulations, but we also explore which individuals would make a voluntary transition into unemployment (ie, the incentives for voluntary transitions into unemployment). This exogenous firing mechanism is a reduced form for the complex choices made by firms, probably after a negotiation of some sort with the potentially affected workforce. ${ }^{9}$ The unemployed can re-enter the labour force after a successful search process. It involves an active job-seeking process (with some underlying costs) and a random process of receiving job offers (characterized by a re-entry wage level). Searching is, therefore, costly and risky in our model. Individuals have to pay the cost (that we model as forgone leisure) upfront, and then wait for uncertainty to materialize. Unlucky unemployed workers may get a too-low-to-be-acceptable wage offer (ie, an offer below the individual's reservation wage, which varies according to his/her particular circumstances). They may not even receive any job offers at all, despite all their efforts. We assume that search costs increase with age, while the chances of receiving a job offer decrease with age in step with the length of the unemployment spell, being also lower for workers with low accrued pension rights (a proxy of permanent income). ${ }^{10}$ During the unemployment spell, income is provided by a public unemployment system, which as described below decreases in generosity with the duration of the spell, while also protecting the pension rights of the unemployed. Theoretically, the unemployed must search for work to be entitled to unemployment protection, but this constraint is not enforced in practice, and a typical moral hazard problem emerges: laid-off workers can use the unemployment protection as an alternative exit route into retirement. They can remain unemployed without searching (a state we refer to as "non-participation"), avoiding in this way the early retirement penalties involved by claiming pensions before the Normal Retirement Age (NRA). A detailed description of this problem and of the techniques used to solve it can be found in García Pérez and Sánchez Martín (2013)). Hence, in our benchmark model non-participation is a perfectly feasible alternative to search or retirement (after the ERA) for the unemployed.

The main behavioural assumption in this model is one of rationality: individuals are modelled as expected utility maximizers, endowed with a correct understanding of the world they live in (in terms of both the institutional structure and the sources of uncertainty). To derive the optimal behaviour, we apply dynamic programming to a recursive formulation of the individual problem. Formally, our rational workers choose the best course of action at each age by comparing the expected discounted utility obtained from the (current and future) flows of income and leisure associated with each decision. These are summarized by the value functions associated with each choice, given age, $\tau$, and the other characteristics of the represented individual:

- Employees (after ERA) remain employed (referred as state "E") or retire (state "R"). We represent their optimal choice at age $\tau$ as the solution of the functional equation

$$
V_{\tau}^{E}(x)=\operatorname{Max}\left\{U_{\tau}^{E}(x), U_{\tau}^{R}(x)\right\}
$$

\footnotetext{
${ }^{9}$ Modelling the objective and constraints of firms and their interactions with workers and their representatives is a very complex task, and a long-term target for this strand of the literature. Hutchens (1999) offers a first approach to these issues within the implicit contract literature.

${ }^{10}$ The robustness of our findings for some of these assumptions is discussed in Appendix C.
} 
with $x=$ \{wage, pension rights $\}$ and where $U^{E}, U^{R}$ stand for the value derived from remaining employed or retiring in this period (and, as implicit in Bellman's optimality, taking the best available choices in subsequent periods). The value resulting from taking the optimal current choice is summarized in $V^{E}$, the Value Function of the employees.

- For the unemployed, three options are available after the ERA: Retirement (R), Search for a new job (S) or unemployment without searching (N). At age $\tau$ rational agents would similarly decide by comparing the value of all the available options:

$$
V_{\tau}^{U}=\operatorname{Max}\left\{U_{\tau}^{S}, U_{\tau}^{N}, U_{\tau}^{R}\right\}
$$

with $x=$ \{previous wage, pension rights, length of the unemployment spell $\}$ and with the same function notation as before $(U$ values are "after the choice" life-cycle values assuming optimal continuation choices until age 70). Before ERA, the problem is similar, albeit without a retirement option.

Unfortunately, closed-form solutions are not available for dynamic, stochastic problems of this kind. Instead, we compute the value functions numerically by value-function iteration, working backwards from the final programming age (70) to our starting age of 55 . The details of both individual life-time preferences and the pension and unemployment protection systems are discussed in the following section.

\subsection{Calibration of the behavioural model}

\subsubsection{Pension and unemployment systems}

The public pension is available on or after the age of 60 (the ERA in the benchmark environment) and demands a complete withdrawal from the labour market. ${ }^{11}$ It combines an individual-specific component and a minimum guaranteed value ${ }^{12}$. The individual-specific payment, $\tilde{B}$, depends on the worker's retirement age $\tau$ and on his/her accrued pension rights, $\hat{w}$ :

$$
\tilde{B}(\hat{w}, \tau)=\mu(\tau) \hat{w}
$$

where $\mu(\tau)$ is an age-dependant replacement rate that reflects a $7 \%$ annual penalty for retirement between the ERA and the NRA, and a $2 \%$ bonus for retirement after the NRA. $\mu(\tau)$ has zero value at any age before the ERA. The workers' accrued pension rights, $\hat{w}$, are computed as a moving average of covered labour earnings over the 15 years immediately preceding retirement: $\hat{w}_{\tau}=\frac{1}{D} \sum_{i=1}^{D} w_{\tau-i}$ with $D=15 .{ }^{13}$ On top of the individual component, there is

\footnotetext{
${ }^{11}$ In Spain, successive legislative changes have delayed the Early Retirement Age from the age of 60 to 61 and 63 , but the value in force during our simulation was still 60 .

${ }^{12}$ Pension payments cannot exceed a legislated maximum (which we also include in the simulations), but whose empirical relevance in our sample is very small.

${ }^{13}$ The real world formula is approximated in our simulations with $\hat{w}_{\tau+1}=\hat{w}_{\tau}+\frac{w-\hat{w}_{\tau}}{D}$. Otherwise, solving the model would require a much larger vector of state parameters (including all previous wages between age $\tau-D$ and $\tau-1)$.
} 
an age-dependent minimum payment, $B_{\min }(\tau)$, which is annually set by the government. The effective pension payment received is, therefore:

$$
B(\hat{w}, \tau)=\max \left\{\tilde{B}(\hat{w}, \tau), B_{\min }(\tau)\right\}
$$

$B_{\min }(\tau)$ takes only two values, with the payment at or after the NRA being higher than the payment available between the ERA and the NRA. Their calibrated values in our simulations are 7.66 and 7.02 (thousand euros in 2008) respectively, which correspond to the averages of the real values in the 2002/2008 interval; that is, in the period used for our simulation sample. Note that the following applies the same calibration criteria (averages of 2002-2008 real values) to all the institutional values present in our model.

The Unemployment protection system. Unemployed workers are entitled to a "contributory" unemployment benefit, $b(w, h)$, equal to $65 \%$ of their previous wage, and available for a maximum of two years. ${ }^{14}$ Due to the existence of a minimum, $b_{\min }$ and a ceiling, $b_{\max }$ on the contributory payment, the direct proportionality of benefits and previous wages is operative only within a narrow range of previous wages. The calibrated values of these institutional constraints are six thousand and 12 thousand euros respectively. On top of income maintenance, the Unemployment Agency protects the pension rights of the unemployed by paying social contributions on their behalf. This policy avoids the depreciation of the unemployeds pension rights, $\hat{w}$, which would otherwise follow from the reduction in current labour income. Contributory unemployment benefits can be received up to the NRA, but not after. The long-term unemployed (those with spells of more than two years) are protected by an unemployment subsidy that is available until the NRA, and whose value is set at 4,120 euros per year.

Both pension and unemployment benefits are financed with social contributions in the form of a fixed proportion of "covered earnings" (total gross labour earnings within a maximum of 33,800 euros and a minimum of 7,490 euros).

\subsubsection{Preference parameters}

Parameters without explicit real world counterparts are calibrated to match certain selected properties of the data. In the case of individual preferences, we assume a time-invariant discount factor $\beta=(1 /(1+r)$ and period utility function of the CRRA type:

$$
u(y, a, e)=\frac{[y(1+\nu(a, e))]^{1-\eta}}{1-\eta}
$$

where $\eta$ is the degree of relative risk aversion, and $\nu(a, e)$ captures the relative value of leisure depending on age and labour state. The left-hand graph in Figure 1 reproduces the parsimonious structure of $\nu$ implemented in the paper ${ }^{15}$. To assign specific values to these pa-

\footnotetext{
${ }^{14}$ The real values are $70 \%$ during the initial six months and $60 \%$ for the rest of the spell. We work with the $65 \%$ average.

${ }^{15}$ We implemented different linear structures for retirees, employees, and the unemployed who engaged in the effort to search. In principle, we considered differences in both the level and growth rate of $\nu$ with age, for each group. Nevertheless, the final specification is very parsimonious, including a baseline leisure value of 0 for employees, different initial leisure levels for retirees and the unemployed ( 0 \& 0.45 respectively), and just one common $6 \%$ growth rate for both groups (which, for retirees, is operative only after the ERA). We have checked that these values are well-aligned with those used in other structural retirement papers (eg, French (2005))).
} 

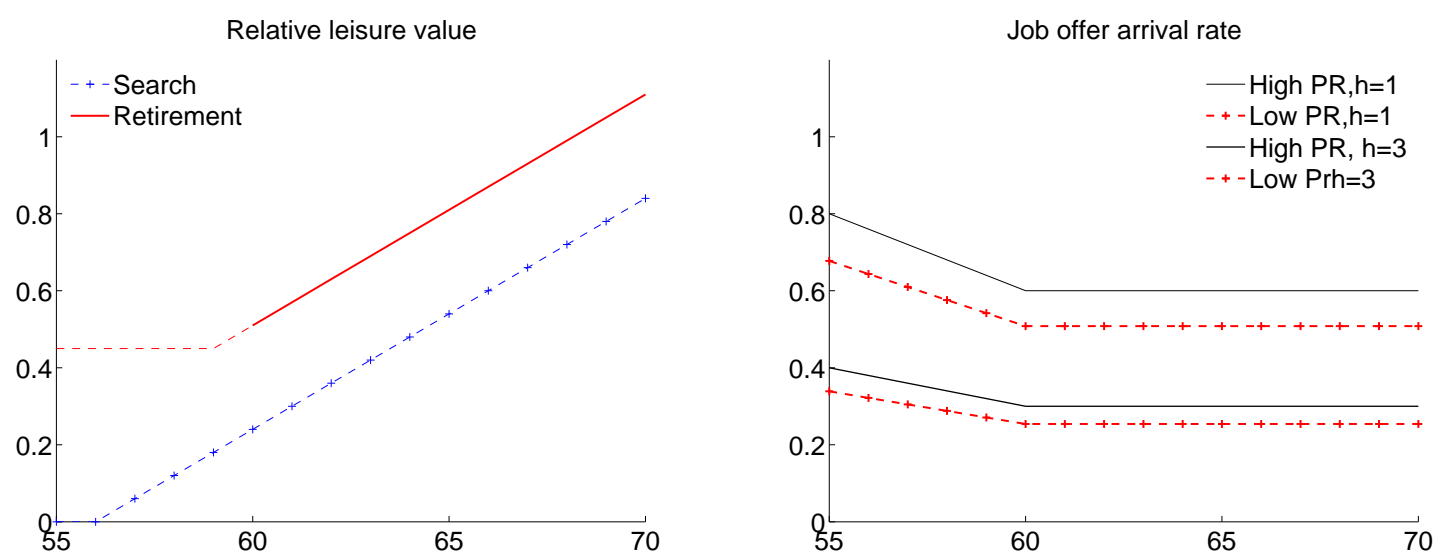

Figure 1: Calibration of the relative value of leisure by age for retirees vs. the unemployed who search (left). Calibration of the exogenous rate of arrival of job offers by age, pension rights (PR) and length of the unemployment spell (right).

rameters, we targeted the age-profiles of retirement rates of employees and unemployed workers in our simulation sample (see Figure 2). ${ }^{16}$ We also implicitly impose the restriction that the selected values should be well within the limits set by previous structural estimations of similar parameters. The values finally implemented are a $3 \%$ discount factor and a $\eta=-1$ value, which imply a CRRA of 2 . Individuals are, therefore, both moderately impatient and moderately risk averse.

\subsubsection{Sources of uncertainty}

Individuals face uncertainty regarding their own survival and labour situation. For the former, we fit the parameters of a Gompertz mortality hazard to reproduce the 2005 mortality rates obtained from INE (Spanish Statistics Office). Matching labour uncertainty is harder, as it manifests itself in several different dimensions: employees are confronted with time-varying firing probabilities, while unemployed workers suffer the uncertainties of the job-seeking process. We have calibrated them as follows:

- Firing rates: we treat the dismissal risk as exogenous, interpreting the empirical rates as mostly reflective of employers interests. ${ }^{17}$ Consequently, we simply apply a smoothed version of the empirical firing rates. At each age, we make a partition of the sample of employees in $3 \times 3=9$ groups, according to their wage level and accrued pension rights. We estimate the firing rate prevailing in each group, at each age from 55 to 65 . The

\footnotetext{
${ }^{16}$ Strictly speaking, all behavioural and labour supply parameters have some influence on each one of the dimensions of labour supply (retirement of employees and the unemployed, and re-entry rates and wages of the unemployed). Nonetheless, extensive simulation of the model uncovered an approximate partition of the parameter space for calibration purposes: retirement is largely controlled by the parameters in the utility function, while re-entry wages and re-entry rates are disproportionately associated to the properties of job offers.

${ }^{17}$ The model solution provides evidence to support our standpoint, as the optimal firing patterns by age (from the perspective of the employees) are very different from the empirically observed ones. This can be appreciated in the bottom-left panel in figure 2 .
} 
sample after 65 is very small, and we assume rates similar to those observed at 65 for more advanced ages. The resulting averages by age are displayed in the bottom-left panel in figure 2 .

- Job-offer arrival rates: The reception of job offers at individual level is unobservable in our sample (accepted offers are covered, but it lacks information on rejected offers). We therefore need to calibrate this arrival rate according to the observed re-entry rates for the different kinds of unemployed. We consider a parsimonious piecewise linear process on age, with different parameter values depending on the duration in unemployment (long/short)and on permanent income (high/low accrued pension rights). The right-hand panel in Figure 1 shows the values that have a good match with the empirical rates: the offer rates decrease in the 55/60 age range and are ordered in the natural way (highest for the short-term/high permanent income unemployed, lowest for the long-term/low permanent income ones).

- Size of wage offers: Once a wage offered has been received, its value is extracted from a log-normal distribution. To reduce the number of parameters, we reproduce the empirical coefficient of variation of log-accepted wages, and only calibrate the mean of the distribution. This parameter is selected to reproduce the average accepted wage by the unemployed who successfully re-enter employment in our sample (bottom-centre panel in Figure 2). The resulting process has a very low average (8,500 euros), but a rather large dispersion (standard deviation of 7,300 euros). This variability is mostly effective on the upside, as minimum wages limit the variability of effective wages on the downside.

\subsubsection{Empirical distributions and Simulation +65}

The distribution of workers according to the state variables (age, duration, previous wages, and accrued pension rights for the unemployed; current wages and accrued pension rights for employees) is directly taken from our estimation sample. Wages and pension rights are continuous state variables, and we need to discretize them as a first step in our numerical solution algorithm. ${ }^{18}$

We have also incorporated a (highly stylized) model of the life-cycle dynamics of employees' wages. Depending on age, we have estimated three curvature values for their life-cycle wages in our estimation sample. Wage growth rates change as individuals move through three broad age groups $(55 / 59,60 / 64$, and 65/69), starting to decrease in the second one. We ignore other individual characteristics for this calculation.

Finally, it should be noted that the empirical sample after 65 is too small to provide a reliable basis for the evaluation of reforms that set 67 as the new NRA. ${ }^{19}$ To deal with this difficulty, we proceed in two steps. First, we compute the new optimal behavioural rules in

\footnotetext{
${ }^{18}$ The resulting multidimensional grid is the Cartesian product of the following sets (as always, values are in thousands of 2008 euros): $\left.\Pi=\begin{array}{llllllllll}8.0 & 12.4 & 16.4 & 20.6 & 25.1 & 29.5 & 33.1 & 36.7\end{array}\right\} \quad \hat{W}=$ $\{7.110 .313 .116 .119 .021 .824 .828 .0\}$. $\Pi$ is used for both the unemployed and employees wages. See García Pérez and Sánchez Martín (2013)) for a more detailed description of the numerical solution procedure.

${ }^{19}$ Note that, in every year between 65 and 69 , we need a minimum sample size on each of our 8 x 8 x 3 "cells" defining the state of the unemployed. For employees, the constraint is less demanding, as there are "only" $8 \times 8$ cells to be covered.
} 

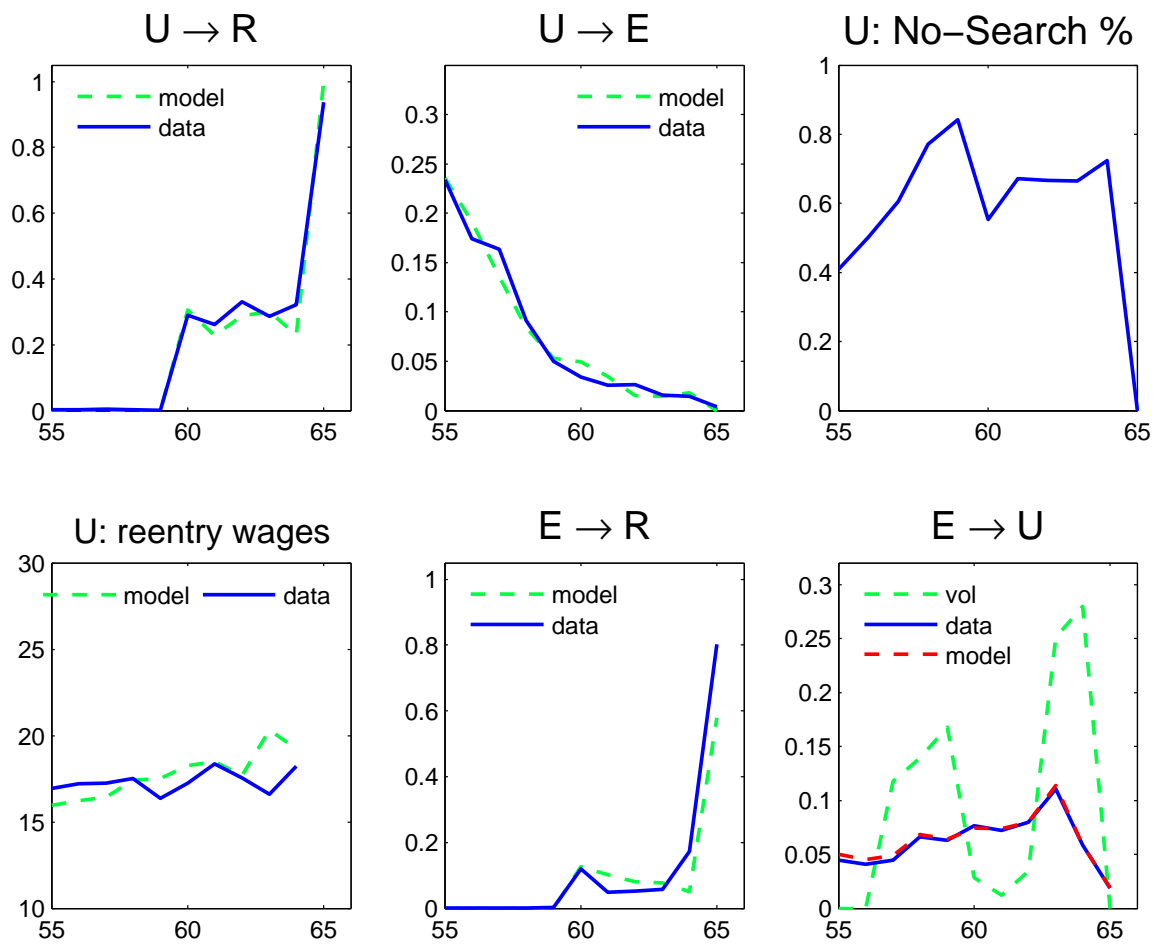

Figure 2: Calibration simulation: model performance vs. empirical data

the reformed institutional environment; then, starting with the empirical distribution at age 55 , we simulate the new sample distribution consistent with optimal behaviour. We are, in effect, considering the total effect of the reform on both individual behaviour and the distribution of the population across the different state variables. Readers should bear this in mind when evaluating the consequences of the reform: aggregate results are a combination of behavioural effects and composition effects.

\subsection{The performance of the calibrated model}

The outcomes of the calibration process are shown in figure 2. The four graphs on the left and the centre panels in the figure compare the data and the model predictions in four critical dimensions: retirement of employees, and retirement, re-entry rates, and wages accepted by the unemployed. Our stylized behavioural model does a good job of capturing the datas main features, both qualitatively and quantitatively. Needless to say, there are differences (especially if one further disaggregates the results), but the fit is good enough to support our reform experiments.

The two remaining panels in the right-hand column in the figure show variables without observable counterparts: they show the incidence of non-participation among the unemployed, and the (theoretical) extension of voluntary dismissals among employees. The latter is confined to the years immediately preceding the key statutory retirement ages (ERA and NRA), but the former is remarkably widespread. Given the structural characteristics of the elderly labour 
market in Spain (with limited job offers, low average re-entry wages, and significant search costs), it is in the interest of a majority of the unemployed not to engage in active job seeking. The characteristics associated with optimal non-participation can be best appreciated by checking the tables of optimal simulated behaviour (provided in Figure 12 in Appendix A). They are further discussed in the results section below.

\section{Simulation Results}

This section explores the two institutional reforms analyzed in the paper. We start by discussing the delay in both the ERA and NRA introduced in Spain by the 2011 reform (ie, "pension reform") in subsection (3.1). Subsequently, we allow for voluntary early retirement at age 60 with a penalized minimum pension (ie, "voluntary ER") in subsection 3.2.

\subsection{Pension Reform: changing the statutory retirement ages}

We consider a straightforward modification of the pension rules described in section 2.2.1. We modify the schedule of age-related penalties, $\mu(\tau)$, to make 67 the new Normal Retirement Age. At the same time, the age when pension benefits are first available is delayed to 63 . The structure of minimum pensions is modified in parallel: the lower guaranteed payment is now available between $63 / 66$, and the higher, post-NRA pension can be claimed by retirees aged 67 or over.

The main economic impacts of these changes are as follows: (i) an across-the-board reduction in pension generosity, and (ii) the virtual impossibility of retirement before 63 (given the extreme form of borrowing constraints assumed in the search model) ${ }^{20}$ As a result, we expect workers to stay in the labour force after 65 in much larger numbers than before the reform. This could generate large savings in pension/unemployment benefits, but also incur large welfare costs. In this section, we quantify all these factors by simulating the calibrated model described in section 2.2.1. Note that,as discussed in section 2.2.4, this poses a significant challenge to the simulation procedure used to calibrate the model. This is because the empirical sample after 65 is too small to provide a reliable basis for the evaluation of the reform. Instead, we compare the new behaviour after the reform with the performance of a simulated version of the benchmark economy. This simulated benchmark uses the endogenous distribution generated by the optimal behaviour in the benchmark environment (rather than the empirical sample distribution). We can thus expand the simulated sample beyond the empirical sample (which, for evaluation purposes, effectively ends at the age of 65 ).

\subsubsection{Labor supply}

To assess the impact on the labour supply of the pension reform, we solve the model numerically and summarize the results with the help of graphs and aggregate measurements. Unfortunately, economic analysis alone is unable to provide closed-form expressions for the labour

\footnotetext{
${ }^{20}$ This restriction is reasonable in a world in which most savings are held in an illiquid form (eg, a property or other forms of fixed assets).
} 
supply changes induced by the reform. Such an analysis may be possible with the retirement behaviour of employees, but we lose the ability to generate clean analytical expressions for the unemployed, or even for employees, once uncertainty is considered. Nevertheless, we conduct a quick review of the theoretical impact of the reform before we engage in full-blown simulations.

We start by considering employees in a deterministic setting ${ }^{21}$. An individual is expected to stop working at age $\tau^{*}$ if the marginal gain of postponing retirement no longer exceeds its marginal cost. Typically, the marginal gains are derived from the additional income obtained from a higher pension, while foregone leisure is the biggest marginal cost. Formally, the marginal gains can be expressed as the product of the change in life-cycle resources, $y^{\prime}$, times the utility value of an extra unit of income, $\lambda$ (the Lagrange Multiplier associated with the life-cycle budget constraint). The pension reform modifies both elements: it has substitution effects derived from the modification of $y^{\prime}$ and has wealth effects captured by $\lambda$ (which is inversely related to the total life-cycle wealth of the individual). We review both in turn.

- Substitution effects of the reform. For an employee with net current wage $w$ and pension benefit $B$, the change in life-cycle wealth resulting from postponing retirement at age $\tau$ is:

$$
y^{\prime}(\tau)=w(\tau)-B(\tau)+B^{\prime}(\tau) \mathcal{A}(\tau)
$$

$B^{\prime}$ is the marginal change in the value of the pension benefit if the individual continues working, and $\mathcal{A}$ measures (in expected, discounted terms) the length of the period during which the individual enjoys the extra pension obtained. In our economy's pension system, $B^{\prime}=\mu(\tau)^{\prime} \hat{w}+\mu(\tau) \hat{w}^{\prime}$. There are incentives to delay retirement if, by doing so, the early retirement penalties are reduced ( $\mu$ increases) and/or the accrued pension rights are increased ( $\hat{w}^{\prime}>0$, which depends on the life-cycle profile of labour income).

The main substitution effect of the pension reform is felt in the second sum of eq. (5): at each age, $B$ is smaller due to the bigger penalties, which lead to smaller replacement rates, $\mu(\tau)$. A second effect is observed in the age range between the old and the new NRA: the old bonus for retirement after 60 is smaller than the standard early retirement penalty $(2$ $\%$ vs. $7 \%$, respectively), which leads to a bigger $B^{\prime}(\tau)$ in those years, thereby creating a greater incentive to remain in work.

- Wealth effects of the reform. As a result of the drop in $B(\tau)$, total life-cycle wealth at each $\tau$ is smaller. This implies a higher marginal utility of income and, ceteris paribus, a bigger $\lambda(\tau)$ and a greater sensitivity to the financial incentives provided by the pension system.

All in all, wealth and substitution effects align to reinforce the incentive to work longer and retire later.

Introducing uncertainty forces us to resort to dynamic programming and value-function representation of workers choices. We can still discuss how the basic trade-offs are modified, depending on whether firing is an exogenous or endogenous process. With an exogenous firing decision, the value of the state of unemployment becomes an additional factor in worker

\footnotetext{
${ }^{21}$ we use the notation in Jiménez-Martín and Sánchez-Martín (2007)), which is an extension of Sheshinski (1978)).
} 
behaviour. If being unemployed implies a loss of welfare, it also reduces the incentive to stay employed discussed above. If, on the other hand, it is advantageous to be fired, this increases the incentive to postpone retirement and stay employed. Things are more complex if the transition into unemployment is a workers voluntary choice. Numerical simulations (of both employees and the unemployed) are needed but, in general, it is especially worth considering voluntary transition in the years immediately preceding ERA \& NRA (ie, use unemployment as an "alternative exit route"). Those choices also reflect a basic income/leisure trade-off: anticipate leisure by paying a price in terms of current income and (depending on personal circumstances) a slight reduction in future pensions.

Outlining the trade-offs faced by the unemployed requires resorting to numerical methods from the onset. ${ }^{22}$ The reform has some effects even before the option of retirement is available (ie, at ages under 60). By changing the value of future retirement and (indirectly) that of employment, the reform changes the incentives to search vs. non-participate. In absolute terms, the value of each reemployment opportunity is smaller after the reform, which should reduce the appeal of searching and re-entering the workforce. Yet the damage inflicted on the alternative non-search option is even greater, especially for those who plan for early retirement at 60 . Take, for example, a worker aged 58 expecting to retire at the earliest possible time. Before the reform, the plan involved two years of unemployment, which are covered by generous contributive unemployment payments and the ring-fencing of his/her previous accrued pension rights. After the reform, the same strategy would add two extra years with only minimal income protection (the unemployment subsidy) and a deeper erosion of previous pension rights.

Finally, once the ERA is reached, the unemployed should weigh an (also weaken) direct retirement option against the aforementioned search/non-participation route. A new incentive for passive, non-searching unemployment may well emerge in the years immediately preceding the new NRA of 67 , but only carefully calibrated quantitative simulations can determine the best course of action for each type of individual.

\section{Simulation Findings}

A summary of the simulated optimal choices of employees and the unemployed in our sample is provided in Tables 1 (with benchmark institutions) and 2 (after pension reform). The left-hand panels in Figures 3 to 5 show the resulting transitions into retirement and employment, while the left-hand panels in Figures 6 and 7 show the in-sample incidence of voluntary non-participation by the unemployed and voluntary transitions into unemployment by employees. Finally, Table 3 provides the average retirement age observed in each one of our simulation scenarios.

The overall image emerging from the comparison of the base and pension reform simulations is clear: the reform is a great success from the labour-supply perspective. All types of workers retire later and have a smaller propensity to "abuse" the system, while the unemployed reenter employment in much bigger numbers than in the base scenario. To explore the results in more detail, Appendix A provides the optimal behaviour by employees in the benchmark

\footnotetext{
${ }^{22}$ A detailed theoretical analysis is included in García Pérez and Sánchez Martín (2013)).
} 

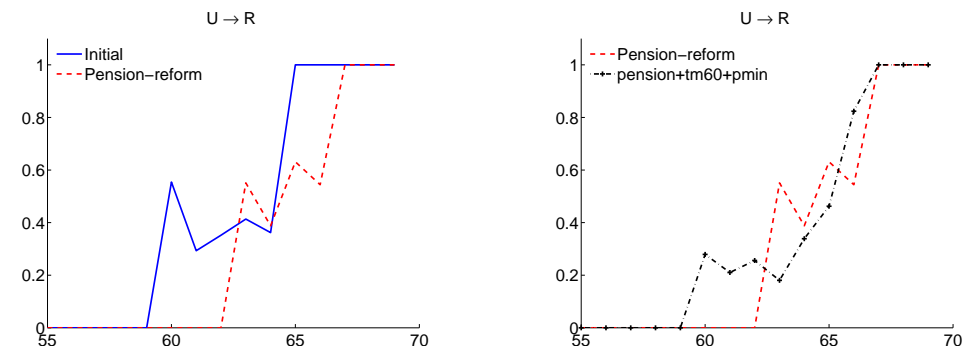

Figure 3: simulated retirement hazards of employees. Left-hand panels: benchmark and pension reform scenarios; Right-hand panels: pension reform and voluntary ER scenarios.
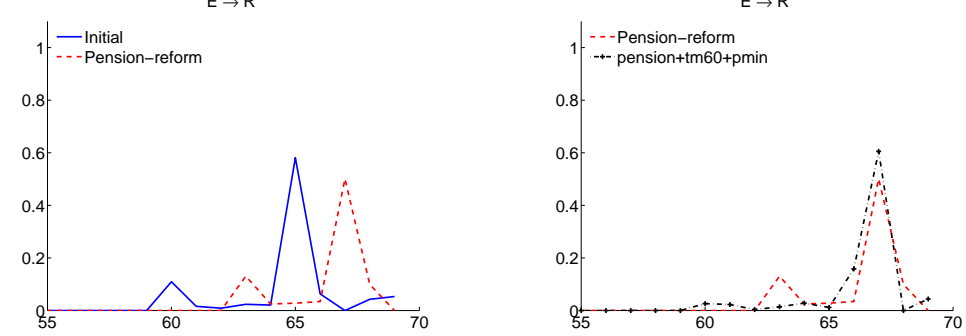

Figure 4: simulated retirement hazards of the unemployed. Left-hand panels: benchmark and pension reform scenarios; Right-hand panels: pension reform and voluntary ER scenarios.
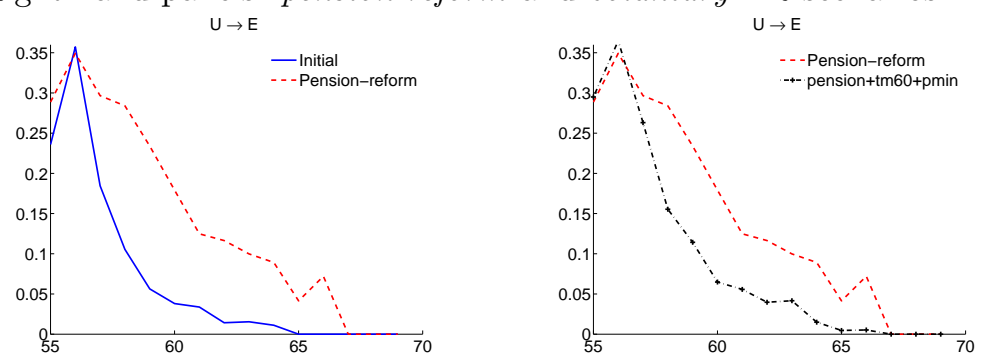

Figure 5: simulated reemployment hazards. Left-hand panels: benchmark and pension reform scenarios; Right-hand panels: pension reform and voluntary ER scenarios.
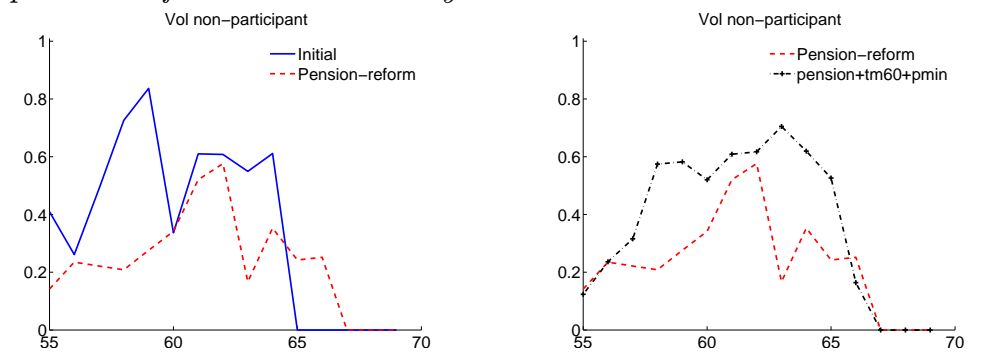

Figure 6: simulated incidence of non-participation among unemployed workers. Left-hand panels: benchmark and pension reform scenarios; Right-hand panels: pension reform and voluntary ER scenarios.
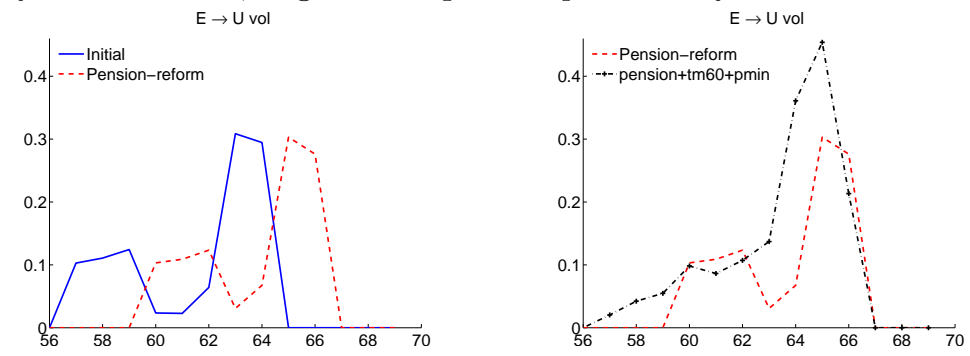

Figure 7: simulated incidence of voluntary unemployment among employees. Left-hand panels: benchmark and pension reform scenarios; Right-hand panels: pension reform and voluntary ER scenarios. 


\begin{tabular}{c|ccc|ccc}
\hline & \multicolumn{3}{|c|}{ Employees } & \multicolumn{3}{c}{ Unemployed } \\
Age & Ret & VolU & Emp & Ret & Search & NP \\
\hline $55 / 59$ & 0.0 & 6.4 & 93.6 & 0.0 & 35.8 & 64.2 \\
$60 / 64$ & 4.1 & 12.2 & 83.7 & 41.4 & 6.8 & 51.8 \\
$65 / 69$ & 26.0 & 0.0 & 74.0 & 100.0 & 0.0 & 0.0 \\
\hline
\end{tabular}

Table 1: Base simulation: Optimal Choices of employees and unemployed workers. Ret= retirement; $V o l U=$ voluntary unemployment; $E m p=$ stay employed; Search = unemployment search for a new job; $N P=$ Non participation by an unemployed (stay unemployed without searching).

\begin{tabular}{c|ccc|ccc}
\hline & \multicolumn{3}{|c|}{ Employees } & \multicolumn{3}{c}{ Unemployed } \\
Age & Ret & VolU & Emp & Ret & Search & NP \\
\hline $55 / 59$ & 0.0 & 0.0 & 100.0 & 0.0 & 76.8 & 23.2 \\
$60 / 64$ & 2.9 & 8.9 & 88.2 & 20.5 & 41.3 & 38.3 \\
$65 / 69$ & 15.1 & 15.5 & 69.4 & 68.7 & 11.9 & 19.4 \\
\hline
\end{tabular}

Table 2: Pension reform: Optimal Choices of employees and unemployed workers

scenario (Figure 12), while Figure 13 shows the changes induced by the pension reform. The two theoretical forces discussed above can be seen clearly in action: workers either delay retirement or shift to voluntary unemployment. Typically, lower income workers increase their opportunistic behaviour, while workers with somewhat higher wages tend to postpone retirement. Yet who exactly is changing behaviour depends on age: around the age of 60 , only low income workers shift behaviour, while around 65 the change in decision can be observed among workers with higher current wages. When we move to the aggregate consequences (by weighting individual behaviour by the size of the simulated sample) things become clearer: a pattern of reinforced labour supply emerges as the outright winner. In the overall sample, there is more employment and less voluntary unemployment between 50 and 64 (Tables 1 and 2, Figures 3 and 7). There is more voluntary unemployment at 65 and 66 (the general age-pattern shifts rightwards with the reform), but the total aggregate impact is small. ${ }^{23}$ The optimal retirement age is a year and a half longer after the reform.

\begin{tabular}{cccc}
\hline & Base & Pension Reform & Voluntary ER \\
\hline Employees & 65.92 & 67.45 & 67.25 \\
Unemployed & 61.16 & 63.87 & 62.44 \\
\hline
\end{tabular}

Table 3: Average simulated retirement ages in our three institutional environments.

\footnotetext{
${ }^{23}$ Recall that we keep to the assumption that all firing is done by employers. The results on voluntary nonparticipation are only for informative purposes.
} 
Appendix A also shows important changes in behaviour induced by the reform on unemployed workers. Again, we see a combination of reactions in opposite directions. At younger ages (before 60), the change is almost wholly towards further job seeking. Between 60 and 64 , the pattern is more mixed: newly unemployed workers $(h=1)$ mostly intensify their search behaviour, but the long-term unemployed follow a different pattern, with increased nonparticipation among those with average or above-average pension rights. Finally, between 65 and the new ERA we see the same mixed pattern among the newly unemployed (while the long-term unemployed remain unaffected). The aggregate consequences are clearer than what one might expect from the mixed pattern of individual reactions. Re-entry hazard rates are spectacularly high, reflecting large gains in search behaviour in the 55/64 age range (Tables 1 and 2, Figures 4 and 5). Nevertheless, the alternative exit route into retirement via non-participation continues to be exploited, especially before the new ERA (between 61 and 63). Its quantitative incidence is, however, smaller than in the 58/59 age range in the benchmark case. The incidence only increases between $65 / 66$, but this is more than offset by the decrease in its use at earlier ages. All in all, the average retirement age is up by around 2 years and 8 months, which is appreciably larger than the increase among employees. It is quite remarkable that although most of the discussion about pension reform is framed within the context of employees behaviour, its effective impact seems to be much larger among the unemployed.

\subsubsection{Costs and Welfare}

The second major rationale for the convenience of pension reform lies in its potential capacity to make large savings on current pension expenditure. To evaluate the performance of the reform in this dimension, we (i) compute the net pension-unemployment cost incurred by each one of the different types of individuals in our model, and (ii) aggregate across different types to arrive at a composite estimation of aggregate costs (eg, total Net Aggregate Costs, NAC, in Table 4). As discussed below, we express the costs saved as a constant annuity to facilitate comparison with our measure of the reforms welfare impact.

The cornerstone of the evaluation is the net cost that each individual represents for the combined public pension/unemployment protection system. It is assessed by computing the present discounted value of all pension/unemployment payments that will be received during an individuals remaining life, net of all contributions to be made in the same period. The calculation reflects the fact that workers can change their labour state in the future, as a result of the exogenous sources of uncertainty in the model (and taking into account also that they will react optimally, according to the institutional environment). As an illustrative example, Appendix B presents the concrete net pension/unemployment costs of a worker with average wage $(16,200$ euros) and the same amount of accrued pension rights, who is observed in four possible labour states (as employee, retiree, unemployed actively seeking job offers, and nonparticipant unemployed). Figure 16 shows the resulting costs in the base scenario with ages varying within the 55/69 interval. A similar calculation is shown in Figure 17 under the reformed institutional setting. A systematic pattern emerges: before the NRA, unemployed workers are the most expensive to support (especially those that "abuse" the system by refusing to search), followed by retirees. The differences tend to decrease with age, becoming quite small after the 


\begin{tabular}{ccccccc}
\hline & \multicolumn{3}{c}{ Employees } & \multicolumn{3}{c}{ Unemployed } \\
& NAC & costs savings & welfare loss & NAC & costs savings & welfare loss \\
\hline Base & 166.56 & - & - & 203.59 & - & - \\
Pension Reform & 134.26 & 2.32 & 3.94 & 167.55 & 2.47 & 6.46 \\
Voluntary ER & 134.16 & 0.01 & -1.78 & 162.28 & 0.44 & -2.75 \\
\hline
\end{tabular}

Table 4: Net Aggregate pension-unemployment Cost and welfare impact in different institutional environments. All figures in thousand euros in 2008.
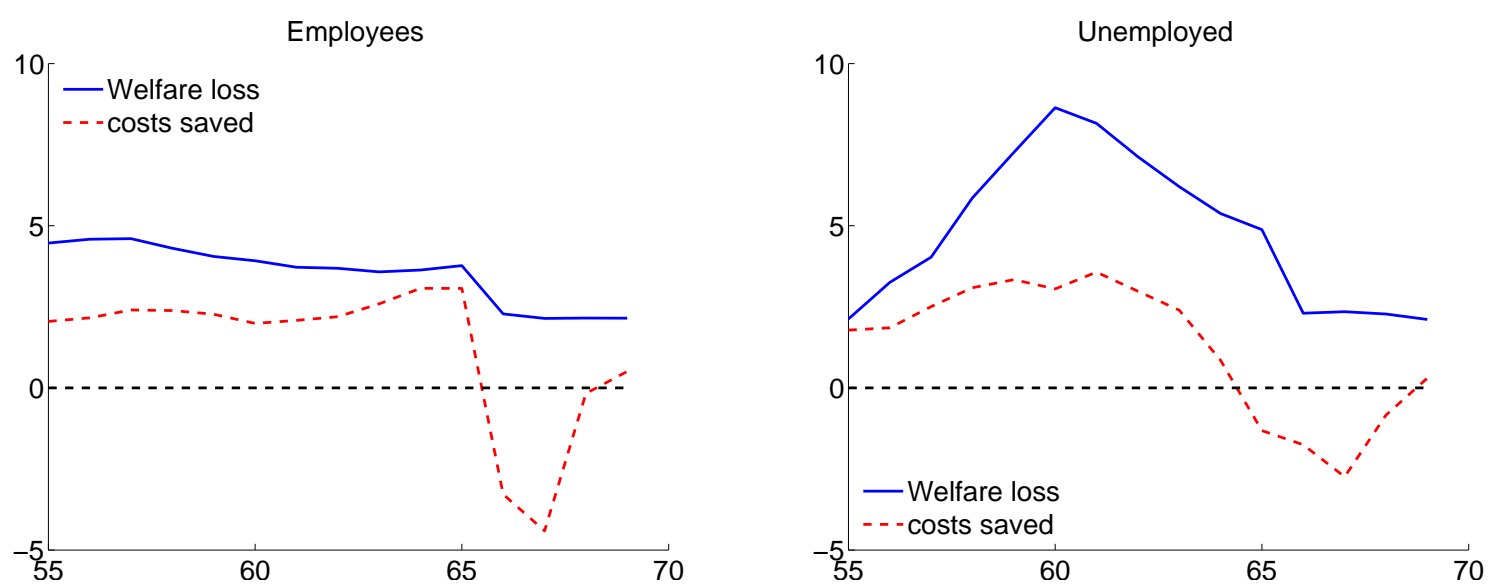

Figure 8: Average cost-savings and welfare losses induced by the pension reform. Annuity values in thousand euros in 2008

NRA. At younger ages, in contrast, non-searching unemployed can be as much as $60 \%$ more expensive than employees of similar characteristics.

The leftmost column in Table 4 shows our "all inclusive" measure of net average costs, NAC (a weighted average of the pension-employment costs across all individuals in our simulation sample). The total effect of the reform in terms of costs is well summarized by comparing the NAC before and after the reform: 166 vs. 134 (thousand euros in 2008) for employees, and 203 vs. 167 for the unemployed. They represent a staggering $20 \%$ reduction for the former and a similarly impressive $18 \%$ for the latter.

How are these large aggregate savings generated? To help with the answer, we further elaborate our cost measurements in two ways: first, we recode the net individual cost as an equivalent constant annuity (still expressed in thousand euros in 2008). ${ }^{24}$ We then compute the "cost-savings" generated by a reform as a weighted average of the differences in the individual annuity costs in the initial and reformed institutional environments. The average cost-savings induced by the reform across the entire sample is also presented in Table 4, while Figure 8 shows more disaggregate results conditional upon employment and age.

Starting with employees, we find fairly uniform cost-savings until the age of 65 . The origin of these savings is clear: the reform induces later retirement, and employees are always "cheaper" than retirees (irrespective of age, see Figures $16 \&$ 17). Cost increases at the ages of 66 and 67

\footnotetext{
${ }^{24}$ This is done to facilitate comparison with the welfare measure introduced later in the section.
} 
due to the change in the sample composition resulting from the reform (the left-hand panel in Figure 15 in Appendix B clarifies this point). All in all, the pension reform results in a 2,300 euro average reduction in the pension/unemployment costs of employees. The unemployed tend to draw less attention in the pension reform debate, but our simulated figures in Table 4 and the right-hand panel in Figure 8 show even greater savings. On average, the expenditure falls by almost 2,500 euros. These savings are mostly obtained from the unemployed in the 58/63 age range. ${ }^{25}$

In the light of these results, it is hard to object to the success of the reform in terms of costcutting, although we cannot reach a definite conclusion until the welfare effects of the reform are also determined. This is the task of the next subsection.

\section{Welfare impact}

To gauge the welfare change induced by the reform, we compute an Equivalent Variation expressed as an income annuity. ${ }^{26}$ For each individual, we rewrite his/her life-cycle utility as an income annuity that generates the same welfare level, and then measure the "welfare loss" induced by the reform simply as the difference in the individual annuity values in the two institutional settings (the annuity value in the base environment minus the annuity in the reformed system). A positive value implies a larger utility in the initial benchmark system. Furthermore, the change in welfare is expressed in euros, which allows a straightforward comparison to be made with the financial calculations discussed above. To obtain an aggregate welfare figure, we compute a weighted average of the individual "welfare losses" across the individuals in the sample. ${ }^{27}$ Figure 8 presents aggregate values at different ages, while the sample-wide averages for employees and the unemployed are once more reproduced in Table 4.

The magnitude of the figures leaves little room for interpretation: the negative welfare impact of the reform largely exceeds the costs saved. With our calibrated utility functions, individuals will be willing to pay far larger amounts to avoid the reform than the size of the costs saved (which, in principle, represent the resources available to compensate the losses created by the institutional change). On average, employee welfare loss is equivalent to an annual reduction of 4,000 euros in income (or almost $75 \%$ more than the costs saved). For the unemployed, the figure is an overwhelming 6,460 thousand euros (or 160\% more than the costs saved by the reform). The details on the age-distribution of the losses are once more to be found in Figure 8: for the unemployed, they increase with age, peaking at 60 . They decrease thereafter, but always outpace the costs saved (and remain positive after 65, when costs are actually increased). Losses are higher for the long-term unemployed and for those with higher accrued pension rights. For employees, the welfare losses are quite stable, but also display a slightly downward trend with

\footnotetext{
${ }^{25}$ After the reform, the average costs in the $65 / 67$ age range increase. This is explained by the change in behaviour previously discussed in combination with the cost patterns by age in Figures $16 \& 17$. Note, in particular, that the relative position of unemployed workers and pensioners shifts at the NRA.

${ }^{26}$ As with the previous cost measures, a detailed description of the welfare measure can be found in García Pérez and Sánchez Martín (2013)).

${ }^{27}$ Strictly speaking, we should compare welfare on an individual basis, but the usual problems with interpersonal welfare comparisons are somewhat less acute in our simulation, as our individuals are assumed to have identical utility functions (at each age).
} 


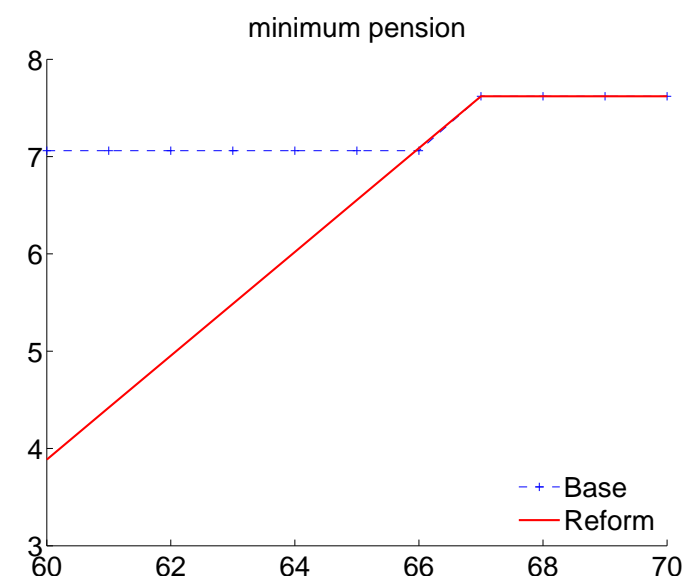

Figure 9: New structure of minimum pension in the Voluntary ER environment

age.

To reach an overall evaluation of the effectiveness of the reform, we must balance its pros and cons. Clearly, it delivers in terms of labour supply and cost-savings, but at the price of huge welfare costs. The size of the welfare losses tips the balance towards a negative overall conclusion. Simply put, the reform is inefficient, and the large welfare losses seem to vindicate the well-known popular opposition to delays in retirement ages. ${ }^{28}$ So we must move forward in our analysis: is there anything that can be done to alleviate the negative impact of the reform? Combining the findings for employees and unemployed workers, it is clear that early retirees suffer disproportionately with the changes. In the next section, we consider a modification to the pension reform intended to present a less aggressive environment to early retirees. Hopefully, the new environment may retain some of the positive aspects of the original reform without producing the same devastating welfare losses.

\subsection{Voluntary Early Retirement Reform}

Among the several factors that may contribute to the high welfare costs of the pension reform, the delay of the ERA to 63 is probably the most outstanding contributor. Recall from Figure 2 in section 2.3 that early retirement at 60 was a very popular choice among long-term unemployed workers (typically preceded by a stage of non-participation unemployment). A relatively high minimum pension made this a very rewarding strategy for the unemployed with small accrued pension rights.

As argued in the Introduction, this possibility creates a classical "moral hazard" problem: the insurance makes sense for some workers (those with genuine difficulties to return to employment), but it is subject to abuse by other workers who can return, but prefer the comfort of claiming unemployment benefits and minimum pensions. Ideally, a good institutional design should target the former and leave the latter without protection. In a context of clearly asymmetric

\footnotetext{
${ }^{28}$ Since November 2006, all Eurobarometer surveys (www.ec.europa.eu/public_opinion) clearly illustrate how, of all the solutions proposed for resolving the pension crisis, increasing the retirement age is the one generating the most opposition among European citizens.
} 
information, the pension/unemployment design should foster the self-selection of workers into the option that is socially more convenient. In this section, we propose what we think is a step in this direction: leave the early retirement option open, but reform the minimum pension mechanism in two ways:

1. Make the payment an increasing function of retirement age, in an effort to draw closer to "actuarial justice" in the provision of minimum pensions.

2. Penalize the level of minimum pensions (at all ages) in the same proportion as the general individual pension is penalized by the pension reform.

To achieve these two goals, we modify the institutional environment in the pension reform to allow early retirement at 60 (ERA $=60$, as in the benchmark) and (ii) apply the same age-conditional replacement rate used in the regular payment, $\mu(\tau)$, to the minimum pension payment. Formally, $B_{\text {min }}(\tau)=\mu(\tau) \hat{B}_{\text {min }}$ with $\hat{B}_{\text {min }}=7.06$ (before NRA) or 7.62 (after NRA). Figure 9 illustrates the resulting minimum payment schedule, which achieves the two targets stated above. We refer to this new environment as the Voluntary Early Retirement (or Voluntary $E R)$ system. In the next two subsections, we compare this new environment with the pension reform system explored in the previous section.

\subsubsection{Labour supply}

Some of the labour supply changes induced by the pension reform are undone, but only partially so. This can be appreciated in the distribution of optimal behaviour in Table 5, in the righthand panel in Figures 3 to 7 and in the average retirement ages in Table 3. Recall also the disaggregated analysis of optimal choices in Figure 14 of Appendix A.

For employees, the impact on retirement is negligible. A small early retirement peak at the ERA reappears, but the aggregate incidence of early retirement is slightly smaller (higher at $60 / 61$ and 66 , but much lower at 63 ). The size of the ERA spike is clearly smaller than in the benchmark, a product of the now heavily penalized minimum pensions. Overall, the average retirement age is down by slightly more than two months. The impact is bigger on the attraction of voluntary unemployment, which makes a timid reappearance in the 58/59 age group, and becomes a definitely important factor around the age of 65 . Nevertheless, the aggregate impact, as gauged in Table 5, is hardly affected (there are drops of around two percentage points in the proportion of employment at each age group).

For the unemployed, we would expect drops in the search effort by those less able to re-enter, and parallel increases in non-participation and early retirement. The simulation results show all these processes in action, with large quantitative consequences. Search effort is down, especially in the 59/64 interval, where it is more than halved (from 41 to 15\%), although the final search intensity is still over double that in the benchmark. As a mirror image, non-participation is up in all age groups. Gains are especially important before 60 (when retirement is not yet available), as well as in the 63/65 interval. Finally, early retirement is back, with the reappearance of the age-60 spike, and an average anticipation of retirement of almost a year and a half. Once again, note that the incidence of early retirement in the new environment is clearly smaller than in 


\begin{tabular}{c|ccc|ccc}
\hline & \multicolumn{3}{|c|}{ Employees } & \multicolumn{3}{c}{ Unemployed } \\
Age & Ret & VolU & Emp & Ret & Search & NP \\
\hline $55 / 59$ & 0.0 & 1.9 & 98.1 & 0.0 & 53.6 & 46.4 \\
$60 / 64$ & 2.0 & 12.2 & 85.8 & 28.2 & 14.9 & 56.9 \\
$65 / 69$ & 18.3 & 14.3 & 67.4 & 54.5 & 1.7 & 43.7 \\
\hline
\end{tabular}

Table 5: Voluntary ER: Optimal Choices of employees and unemployed workers

the benchmark, and that the average retirement age is much higher for both employees and unemployed workers.

\subsubsection{Costs and Welfare}

The labour-supply impact of this reform seems rather discouraging, but a fair evaluation of the reform can only be achieved after answering two additional questions:

1. Does the dismal labour-supply performance lead to a parallel deterioration of the financial conditions of the pension/unemployment system?

2. Does the reform recoup a sizable part of the welfare costs induced by the pension reform?

Table 4 and Figure 10 provide the answers to these questions. In terms of financial costs, most of the action involves the unemployed. Two opposite forces are in action: on the one hand, less job search and more voluntary non-participation should increase the reforms "tax bill". On the other hand, there is more early retirement, a behaviour that is more heavily penalized after the reform. Figure 10 reveals that the latter process predominates after the age of 60 . There is no early retirement before the ERA, and the reform results in higher net pension/unemployment expenses (ie, negative "cost saved"). Regarding the entire subsample of unemployed workers, there is a small reduction in average cost, equal to an annuity expense of 440 euros less per unemployed worker, on average. For employees, the changes in average costs by age are very small, and the final overall balance is essentially unchanged. These findings are a direct reminder of a simple principle: there is no reason to expect a significant fall in the costs of early retirement if it is allowed on roughly actuarially fair terms.

Regarding welfare, we would ex ante expect welfare gains (ie, negative welfare losses) from the reform. ${ }^{29}$ The size of the average gains is quite remarkable: 2,750 euros per annum for the unemployed, and 1,800 euros for employees. These figures amount to $40 / 45 \%$ of the welfare damage inflicted by the pension reform. The gains are evenly spread across all age groups for both employees and the unemployed, although somewhat smaller gains are observed after 63 for the latter group.

\footnotetext{
${ }^{29}$ Workers may simply ignore the option of earlier retirement offered by the reform. Yet note that, for the small group of workers entitled to minimum pensions at or after 63, the pension payment under the new system would be smaller than under the pension reform.
} 

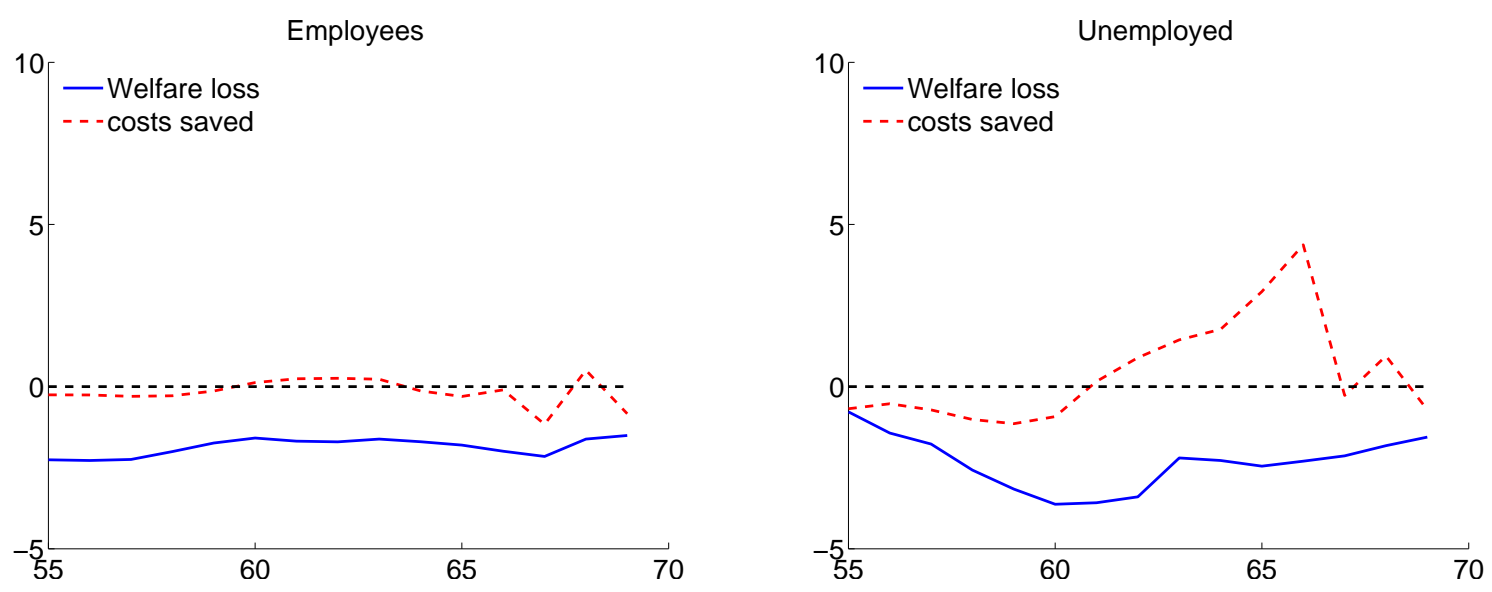

Figure 10: Financial and welfare comparison of the Voluntary ER vs. the pension reform environments.
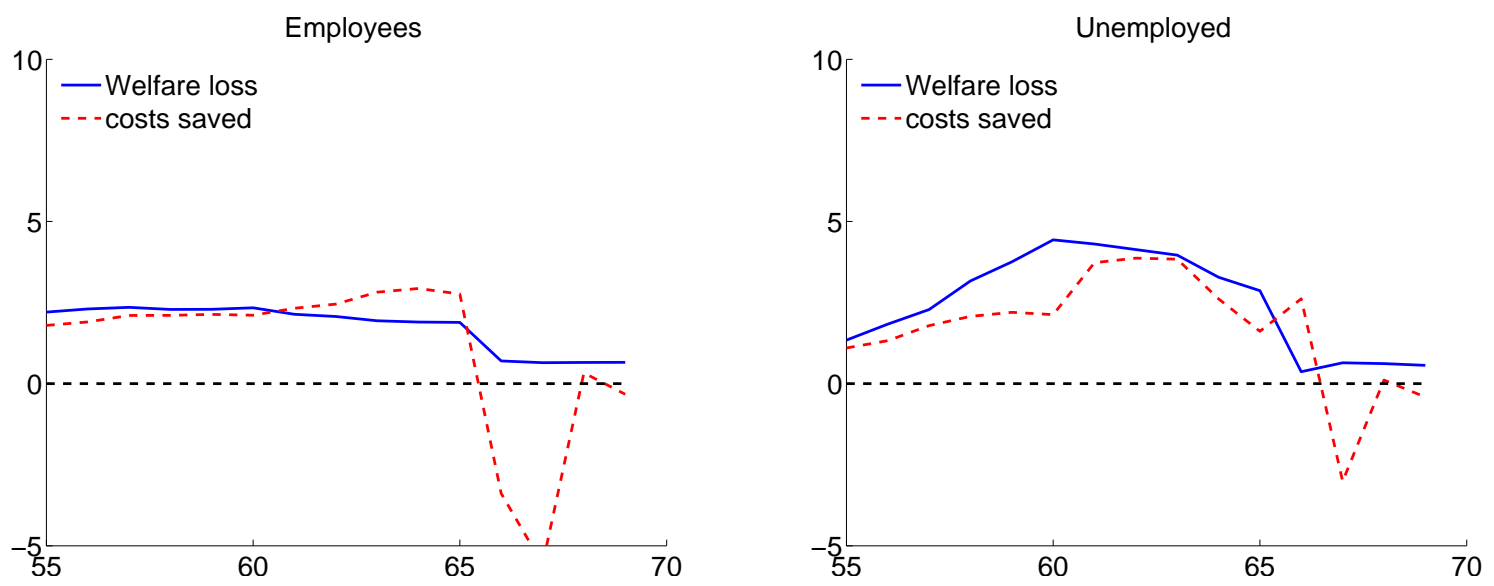

Figure 11: Financial and welfare comparison of the Voluntary ER vs. the benchmark environments.

Overall, the voluntary ER reform seems an interesting alternative to the simple delay in all statutory retirement ages. Compared with the initial benchmark environment, the new institutional setting has appreciably more labour supply and less joint pension-unemployment expenditure. This is achieved at the expense of some "non-compensable" welfare losses, but these are relatively modest. For employees, the average annual welfare losses of 2,200 euros are lower than the 2,300 euros of costs saved, making it theoretically possible to compensate the losers with a tailor-made system of transfers (Figure 11 shows the costs saved and the welfare losses by age). For the unemployed, the losses are higher: 3,600 euros versus 2,600 euros of costs saved. Nevertheless, the gap is narrow enough to justify additional research into the mechanisms that allow early retirement with actuarially fair adjustments in pensions. 


\section{Concluding remarks}

Financially constrained PAYG pension systems all around the world are resorting to delays in their key statutory ages, with 67 becoming the new "normal" retirement age in many European countries. At the same time, the age when pension benefits can be first claimed has also been consistently raised across OECD countries. These policy measures are mostly rationalized on two grounds: to improve the financial prospects of pension systems and foster the labour supply of older workers. They are typically designed from the perspective of the transition of employees into retirement, but a large body of empirical and theoretical research has revealed a richer set of interactions. Other social programmes (especially unemployment protection schemes) can be turned into alternative early retirement routes, with far-reaching implications (as the rapidly growing body of empirical evidence covered in section 1 makes clear). The aim of this paper is to shed light on this set of complex interactions. We explore the effects of changes in the Spanish pension systems key "legal ages" on the behaviour and incentives of both employed and unemployed workers. We use an improved version of the search model first used in García Pérez and Sánchez Martín (2013)) as our theoretical environment. This setting suitably captures the complex network of interactions created by the pension and unemployment protection systems.

The model is carefully calibrated to reproduce the basic empirical patterns observed in a large sample of Spanish workers in 2002/2008. This gives us confidence in its ability to generate reasonable quantitative predictions of the consequences of delaying the NRA from 65 to 67 and the ERA from 60 to 63 . In terms of labour supply, our results basically show that employees largely react to the new incentives introduced by the reform with a widespread postponing of voluntary retirement. This is clearly consistent with the received wisdom from a number of previous studies (see Staubli and Zweimüller (2013), for example). Second, we find that the reform also affects the use of unemployment as an alternative exit route to retirement. The results in this dimension are, however, more intriguing: the tendency the unemployed have to resort to voluntary non-participation is less acute at older ages. The fear of a sharp rise in unemployment in response to pension reform seems overblown. Actually, the reform renders the previously prevailing tendency to take refuge in unemployment before the ERA/NRA much less convenient. We thus find that, without changing unemployment rules, pension reform has the (perhaps unintended) consequence of making the voluntary non-participation exit route much harder. In line with recent empirical findings (Giesecke and Kind (2013)), our model predicts a surge in the search effort of the unemployed.

The financial consequences of the reform are also very satisfactory. We quantify the costs of early retirement for employees and the extra expense that the unemployed (especially nonparticipants) represent for the social protection system. Our finding of a significant cost-saving among employees is not a surprise, but we also find that the savings from the unemployed are even higher. Unfortunately, such a rosy assessment of the reform is shattered when welfare losses are precisely quantified. Pension reform is damaging for employees, but its impact on the unemployed is truly devastating, with losses that more than double the savings achieved in terms of costs. This result is a dramatic reflection on the poor conditions that the unemployed face in the Spanish labour market. It also reflects the large costs involved in job seeking, especially for the long-term unemployed. 
A successful pension reform should strike a better balance between providing the right incentives and protecting the genuinely impaired. Our results indicate that more research is needed in this important dimension. As a first step, we explore an amendment of the pension reform that maintains the pre-existing ERA at 60 (the "Voluntary ER reform"). At the same time, we reform minimum pensions to improve the systems actuarial fairness. The minimum benefits are now reduced in the same proportion as the individual benefits, being also subject to the same early retirement penalties as regular pensions. This is a crucial step to preserve part of the reforms financial achievements without inflicting the same welfare damage. The results of this second reform are not perfect, but they are an encouraging first step. Labour supply is probably reduced (when compared to the post-reform scenario), but it is still significantly larger than in the pre-reform environment. Remarkably, the new reform does not diminish the financial accomplishments of the original pension reform. It actually produces some small extra financial savings among employees. Of course, the key aspect is welfare, and the consequences in this dimension are good. Allowing the unemployed with poor labour market prospects to self-select into early retirement recovers between 40 and $45 \%$ of all the welfare losses induced by the pension reform.

If we take the (theoretical) perspective that the costs saved by the reform could be used to compensate the welfare damaged inflicted on those workers losing out, we may argue that this "Voluntary ER reform" approaches Pareto neutrality. There are small net gains for employees that may compensate for the still important losses suffered by the unemployed. However, given that the group of employees is larger (and making some bold assumptions in terms of interpersonal welfare comparison,) we could argue for an overall result close to neutrality. Although more research is needed before such a statement is confirmed, our quantitative exploration constitutes a suggestive first step. Of course, we need to gather more data on how these reforms would change the labour market for workers aged over 65 . We also need to further explore the robustness of our welfare findings regarding the choice of the utility function (including "prospect" versions in the behavioural perspective). Finally, the role of the firm should eventually be taken into account in the formal calculations. Nevertheless, policy makers are proceeding with the reforms at this very moment. It is the responsibility of the academic community to provide them with better theoretical guidance by pursuing this lengthy research agenda. 


\section{References}

Benitez-Silva, H., M. Buchinsky, Chan H., Rust, J. and Sheidvasser S. (1999), "An empirical analysis of the social security disability application, appeal and award process", Labour Economics, vol. 6, pp. 147-178.

Boeri T. and J. van Ours (2013), The Economics of Imperfect Labor Markets, Second Edition, Princeton University Press, New Jersey.

Boldrin, M., S. Jiménez-Martín and F. Perachi (2004) "Micro-modelling of Social Security in Spain" in Gruber J. and D. Wise ed. "Social Security programs and retirement around the world", Chapter 9. NBER. University of Chicago Press.

Borsch-Supan A. (2000) "Incentive effecs of social security on labor force participation: evidence in Germany and across Europe", Journal of Public Economics, vol. 78 pp. $25-49$.

Cairó, I. (2010) "An empirical analysis of retirement behaviour in Spain: partial versus full retirement," SERIEs, Journal of the Spanish Economic Association, vol. 1(3), pp. 325-356.

Cremer H. and P. Pestieau (2003): "The Double Dividend of Postponing Retirement", International Tax and Public Finance, vol. 10, pp. 419-434.

Cremer, H., J.M. Lozachmeur and P. Pestieau (2004): "Social security, variable retirement age and optimal income taxation", Journal of Public Economics, vol. 88, pp. 2259-81.

Dorn D. and A Sousa-Poza (2010), "Voluntary' and 'involuntary' early retirement: an international analysis", Applied Economics, vol. 42(4), pp. 427-438.

French E. (2005). "The Effects of health, wealth, and wages on labor supply and retirement behavior", Review of Economic Studies, vol. 72, pp. 395-427.

de la Fuente A. and R. Doménech (2012). "The financial impact of Spanish pension reform: A quick estimate", BBVA Working Papers No. 12/12.

García-Pérez J.I. and A. Sánchez-Martín (2013): "Fostering job search among older workers: the case for pension reform", MIMEO, Under evaluation in Fiscal Studies.

García-Pérez J.I., S. Jiménez-Martín and A. Sánchez-Martín (2013): "Retirement incentives, individual heterogeneity and labor transitions of employed and unemployed workers", Labour Economics, vol. 20, pp. 106-120.

Giesecke M. and M. Kind (2013), "Bridge Unemployment in Germany: Response in Labour Supply to an Increased Early Retirement Age" Ruhr Economic Papers 0410, RheinischWestfälisches Institut für Wirtschaftsforschung.

Gruber J. and D. Wise (1999), Social Security and Retirement around the World. NBER. University of Chicago Press.

Gruber J. and D. Wise (2004), Social Security and Retirement around the World: micro estimation. NBER. University of Chicago Press. 
Gruber J. and D. Wise (2007), Social Security and Retirement around the World: fiscal implications. NBER. University of Chicago Press.

Hairault J.O., F. Langot and T. Sopraseuth (2010): "Distance to Retirement and Older Worker's employment: the case for delaying the retirement age", Journal of the European Economic Association, vol. 8(5), pp. 1034-1076.

Hutchens, R. (1999): "Social Security Benefits and Employer Behavior: Evaluating Social Security Early Retirement Benefits as a Form of Unemployment Insurance", International Economic Review, vol. 40(3), pp. 659-678

Jiménez-Martín, S. and A.R. Sánchez-Martín (2004), "The effects of pension rules on retirement monetary incentives with an application to pension reforms in Spain", Hacienda Pública Española, vol. 169, pp. 35-66.

Jiménez-Martín S. and A. R. Sánchez Martín (2007), "An evaluation of the life cycle effects of minimum pensions on retirement behavior", Journal of Applied Econometrics, vol. 22, pp. 923-950.

Jiménez-Martín, S. JM Labeaga and C. Vilaplana (2006), "A sequential model for older workers' labor transitions after a health shock", Health Economics, vol. 15(9), pp. 10331054 .

Kyyrä, T. , Ollikainen, V. (2009), "To search or not to search? The effects of UI benefit extension for the older unemployed", Journal of Public Economics, vol. 92(10-11), pp. 2048-2070.

Lammers M., H. Bloemen and S. Hochguertel (2013), "Job search requirements for older unemployed: Transitions to employment, early retirement and disability benefits", European Economic Review, vol. 58(C), pp. 31-57.

Manuelli R.E, A. Seshadri and Y. Shin (2012), "Lifetime Labor Supply and Human Capital Investment", Working Paper 2012-004A, Federal Reserve Bank of St Louis.

Munnnell, A. and A. Yanyuan Wu (2012), "Are aging baby boomers squeezing young workers out of jobs?", Center for retirement research at Boston College, Working Paper $12-18$.

OECD (2013): "Recent pension reforms and their distributional impact", in Pension at a Glance 2013: OECD and G20 Indicators, Chapter 1, pp. 17-58, OECD, Paris.

Pestieau, P. (2001): "Are we retiring too early?", Ifo Studien, vol. 47, pp. 263-281,

Pestieau, P. and J.M. Lozachmeur (2008): "Social security and retirement decision: a positive and normative approach", Journal of Economic Surveys, vol. 22, pp. 213-233.

Rust J and C Phelan (1997), "How social security and Medicare affect retirement behaviour in a world of incomplete markets", Econometrica, vol. 65, pp. 781-831.

Rust, J., M. Buchinsky and H. Benitez-Silva (2002), "Dynamic structural models of retirement and disability", MIMEO.

Samwick A (1998). "New evidence on pensions, social security and the timing of retirement", Journal of Public Economics, vol. 70, pp. 207-236. 
Eytan Sheshinski, (1978) "A Model of Social Security and Retirement Decisions", Journal of Public Economics, 10, 337-360.

Staubli, S., Zweimüller J, (2013) "Does raising the early retirement age increase employment of older workers?", Journal of Public Economics, vol. 108, pp. 17-32.

Stiglitz, J and Y. Yun (2005), "Integration of unemployment insurance with retirement insurance", Journal of Public Economics, vol. 89, pp. 2037-2067.

Van der Klaauw W. and K.I. Wolpin (2008), "Social Security and the Savings and Retirement Behaviour of low income Households", Journal of Econometrics, vol. 145(1-2), pp. $21-42$.

Vestad O.L. (2013), "Labour supply effects of early retirement provision?", Labour Economics, vol. 25, pp. 98-109.

Wise D. (2012), Social Security and Retirement around the World: Historical Trends in Mortality and Health, Employment, Disability Insurance Participation and Reforms. NBER. University of Chicago Press. 


\section{APPENDIX}

\section{A Optimal behavior}

This sections presents an illustrative summary of the policy functions of employees and unemployed workers in the three institutional environments considered in the paper. Figure 12 starts with benchmark economy, showing the optimal choices of short term unemployed $(h=1)$, long term unemployed $(\mathrm{h}=3)$ and employees in a number of selected ages. The changes created by the delay of the statutory pension ages (pension reform) are illustrated in Figure 13, while the changes resulting from allowing early retirement (with penalized minimum pensions) are shown in Figure 14.

The structure of the arrays is the same in all Figures, but the information presented depends of the environment considered. For the unemployed, each cell is defined by a combination of the wage enjoyed in the preceding employment spell, $\pi$, and of the level of accrued pension rights, $\hat{w}$. These variables take values in the discretized sets $\Pi \times \hat{W}$ reproduced in footnote 18 . Previous wages are arranged in an increasing fashion from the top down, while accumulated pension rights growth with the column from left to right. For the employees, each cell in an array reflects a combination of current wage $w$ and accrued pension rights $\hat{w}$ belonging to the same $\Pi \times \hat{W}$ space.

The arrays in Figure 12 display the optimal decision rules of employees and the unemployed at some particular ages. The decision shown in the cell defined by the $i$-row and $j$-column, $d_{i, j}$, is the optimal behavior for the individual whose previous wage is the i-th element of $\Pi$ and whose pension rights are given by the $\mathrm{j}$-th element of $\hat{W}$. For the unemployed, $d_{i, j}$ takes the value " 1 " when search is the optimal choice; " 0 " if it is optimal to retire; and "N" if non-participation is best. For the employees, $d_{i, j}$ takes the value " 1 " when staying employed is best; "0" if it is optimal to retire; and "V" if a transition to unemployment is the most valuable alternative.

The arrays in Figure 13 display the changes in the optimal choices resulting from the pension reform. In this case, $d_{i, j}$ takes the value " 1 " to represent a change from non-participation into search and "2" for a change from retirement to search. Codes "4" and "5" indicate similar changes into retirement (" 4 " for a change from initial non-participation and " 5 " for a previously searching unemployed). Finally codes "7" and "8" reflect transitions into non participation from retirement and searching, respectively. For the employees the number of possible changes is smaller and the code is simpler: $d_{i, j}$ is " 1 " when the best options shifts from voluntary unemployment in the benchmark to staying employed under the reform. "2" is for changes from retirement to employment; "4" and "5" for changes into retirement (from voluntary unemployment and employment, respectively) and "7" and "8" for changes into voluntary unemployment (from previous choices of retirement and employment, respectively). 
Unemployed $\mathrm{h}=1$

age: $\begin{array}{rrrrrr}56 & 58 & 60 & 62 & 65 & 67\end{array}$

11111111 | 1111NNNN | 111N0000 | 11000000 | 00000000 | 00000000

$11111111 \mid 1111$ NNNN | 111 NNNOO | 1 NNN0000 | $00000000 \mid 00000000$

$11111111 \mid 1111$ NNNN | 111 NNNNN | 1 NNNNN00 | 00000000 | 00000000

11111111 | 1111 NNNN | 11 NNNNNN | 1 NNNNNNO | 00000000 | 00000000

11111111 | 111 NNNNN | 11 NNNNNN | 1 NNNNNNN | 00000000 | 00000000

11111111 | 111 NNNNN | 11 NNNNNN | NNNNNNNN | $00000000 \mid 00000000$

11111111 | 111 NNNNN | 1 NNNNNNN | NNNNNNNN | 00000000 | 00000000

1111111 | 111 NNNNN | 1 NNNNNNN | NNNNNNNN | 00000000 | 00000000

Unemployed $\mathrm{h}=3$

age: $\begin{array}{llllll}56 & 58 & 60 & 62 & 65 & 67\end{array}$

NNNNNNNN | NNNNNNNN | $00000000|00000000| 00000000 \mid 00000000$ NNNNNNNN | NNNNNNNN | $00000000|00000000| 00000000 \mid 00000000$ NNNNNNNNN | NNNNNNNNN | $00000000|00000000| 00000000 \mid 00000000$ NNNNNNNN | NNNNNNNN | $00000000|00000000| 00000000 \mid 00000000$ NNNNNNNN | NNNNNNNN | $00000000|00000000| 00000000 \mid 00000000$ NNNNNNNN | NNNNNNNNN | $00000000|00000000| 00000000 \mid 00000000$ NNNNNNNN | NNNNNNNN | $00000000|00000000| 00000000 \mid 00000000$ NNNNNNNN | NNNNNNNN | $00000000|00000000| 00000000 \mid 00000000$

\footnotetext{
Employees

age: $\begin{array}{llllll}56 & 58 & 60 & 62 & 65 & 67\end{array}$

11111111 | V1VVVVVV | OVV00000 | OV000000 | 00000000 | 00000000

$11111111|11111111| 1111 \mathrm{~V} 000|11 \mathrm{~V} 00000| 10000000 \mid 10000000$

$11111111|11111111| 11111 \mathrm{VVV}|111 \mathrm{VV} 000| 11000000 \mid 11000000$

$11111111|11111111| 11111111|11111 \mathrm{VV} 0| 11100000 \mid 11100000$

$11111111|11111111| 11111111|11111111| 11110000 \mid 11110000$

$11111111|11111111| 11111111|11111111| 11111100 \mid 11111000$

$11111111|11111111| 11111111|11111111| 11111100 \mid 11111100$

$11111111|11111111| 11111111|11111111| 11111110 \mid 11111110$
}

Figure 12: Optimal labor decisions by age in the benchmark environment 
Unemployed $h=1$

Age: $\begin{array}{llllll}56 & 58 & 60 & 62 & 65 & 67\end{array}$

$00000000|00001111| 00012222|00222777| 22000000 \mid 00000000$ $00000000|00001111| 00011122|01112277| 22200000 \mid 00000000$ $00000000|00001111| 00011111|01111177| 22277000 \mid 00000000$ $00000000|00001111| 00111111|01111107| 22277700 \mid 00000000$ $00000000|00011111| 00111110|01111000| 22277770 \mid 00000000$ $00000000|00011111| 00111100|11111000| 22277770 \mid 00000000$ $00000000|00011111| 01111100|11111000| 22777770 \mid 00000000$ $00000000|00011111| 01111100|11111000| 22777770 \mid 00000000$

Unemployed $h=3$

Age: $\begin{array}{rrrrrr}56 & 58 & 60 & 62 & 65 & 67\end{array}$

$00000000|01100000| 22277777$ | 22277777 | $00000000 \mid 00000000$ $00000000|01100000| 22277777|22277777| 00000000 \mid 00000000$ $00000000|01100000| 22277777|22277777| 00000000 \mid 00000000$ $00000000|01100000| 22277777$ | 22277777 | $00000000 \mid 00000000$ $00000000|01100000| 22277777|22277777| 00000000 \mid 00000000$ $00000000|01100000| 22277777|22277777| 00000000 \mid 00000000$ $00000000|01000000| 22277777|22277777| 00000000 \mid 00000000$ $00000000|01000000| 22277777$ | 22277777 | $00000000 \mid 00000000$

Employees

Age: $\begin{array}{llllll}56 & 58 & 60 & 62 & 65 & 67\end{array}$ $00000000|10111111| 70077777|70777777| 00000000 \mid 00000000$ $00000000|00000000| 00001222|00122777| 87700000 \mid 00000000$ $00000000|00000000| 00000111|00011227| 00777000 \mid 00000000$ $00000000|00000000| 00000000|00000112| 00077700 \mid 00000000$ $00000000|00000000| 00000000|00000000| 00002222 \mid 00000000$ $00000000|00000000| 00000000|00000000| 00000022 \mid 00000200$ $00000000|00000000| 00000000|00000000| 00000022100000020$ $00000000|00000000| 00000000|00000000| 00000002 \mid 00000000$

Figure 13: Change in the optimal labor decisions of employed and unemployed workers in the reformed environment $(\mathrm{ERA}=63 ; \mathrm{NRA}=67)$ versus the benchmark economy. Code of changes for the unemployed: $1=\mathrm{N} 1 ; 2=01 ; 4=\mathrm{N} 0 ; 5=10 ; 7=0 \mathrm{~N} ; 8=1 \mathrm{~N} ;$ Code of changes for employees: $1=\mathrm{V} 1 ; 2=01 ; 4=\mathrm{V} 0 ; 5=10$; $7=0 \mathrm{~V} ; 8=1 \mathrm{~V}$; 
Unemployed $h=1$

Age: $\begin{array}{llllll}56 & 58 & 60 & 62 & 65 & 67\end{array}$

$00000000|00000088| 00008855|00085444| 08000000 \mid 00000000$

$00000000|00000088| 00008888|00088844| 08800000 \mid 00000000$

$00000000|00000088| 00008888|00888800| 08800000 \mid 00000000$

$00000000|00000088| 00008888|00888800| 08800000 \mid 00000000$

$00000000|00000888| 00088880|00888000| 88800000 \mid 00000000$

$00000000|00000888| 00088800|00888000| 88800000 \mid 00000000$

$00000000|00000888| 00088800|08888000| 88000000 \mid 00000000$

$00000000|00000888| 00088800|08888000| 88000000 \mid 00000000$

Unemployed $\mathrm{h}=3$

Age: $\begin{array}{llllll}56 & 58 & 60 & 62 & 65 & 67\end{array}$

$00000000|08800000| 88804444|88544444| 70000000 \mid 00000000$

$00000000|08800000| 88804444|88544444| 70000000 \mid 00000000$

$00000000|08800000| 88804444|88544444| 70000000 \mid 00000000$

$00000000|08800000| 88804444|88544444| 70000000 \mid 00000000$

$00000000|08800000| 88804444|88544444| 70000000 \mid 00000000$

$00000000|08800000| 88804444|88544444| 70000000 \mid 00000000$

$00000000|08000000| 88804444|88544444| 70000000 \mid 00000000$

$00000000|08000000| 88804444|88544444| 70000000 \mid 00000000$

Employees

Age: $\begin{array}{llllll}56 & 58 & 60 & 62 & 65 & 67\end{array}$

$00000000|00888888| 00000444|00044444| 70000000 \mid 00000000$

$00000000|00000000| 00000888|00088444| 00000000 \mid 50000000$

$00000000|00000000| 00000000|00008884| 08004000 \mid 00000000$

$00000000|00000000| 00000000|00000088| 00800000 \mid 00000000$

$00000000100000000|00000000| 00000000|00000005| 00000000$

$00000000|00000000| 00000000|00000000| 00000000 \mid 00000500$

$00000000|00000000| 00000000|00000000| 00000000 \mid 00000050$

$00000000100000000|00000000| 00000000|00000000| 00000000$

Figure 14: Change in the optimal labor decisions of employed and unemployed workers in the environment with Voluntary Early Retirement $(\mathrm{ERA}=60)$ vs the reformed environment $(\mathrm{ERA}=63)$. Code of changes for the unemployed: $1=\mathrm{N} 1 ; 2=01 ; 4=\mathrm{N} 0 ; 5=10 ; 7=0 \mathrm{~N} ; 8=1 \mathrm{~N}$; Code of changes for employees: $1=\mathrm{V} 1 ; 2=01 ; 4=\mathrm{V} 0 ; 5=10 ; 7=0 \mathrm{~V} ; 8=1 \mathrm{~V}$; 

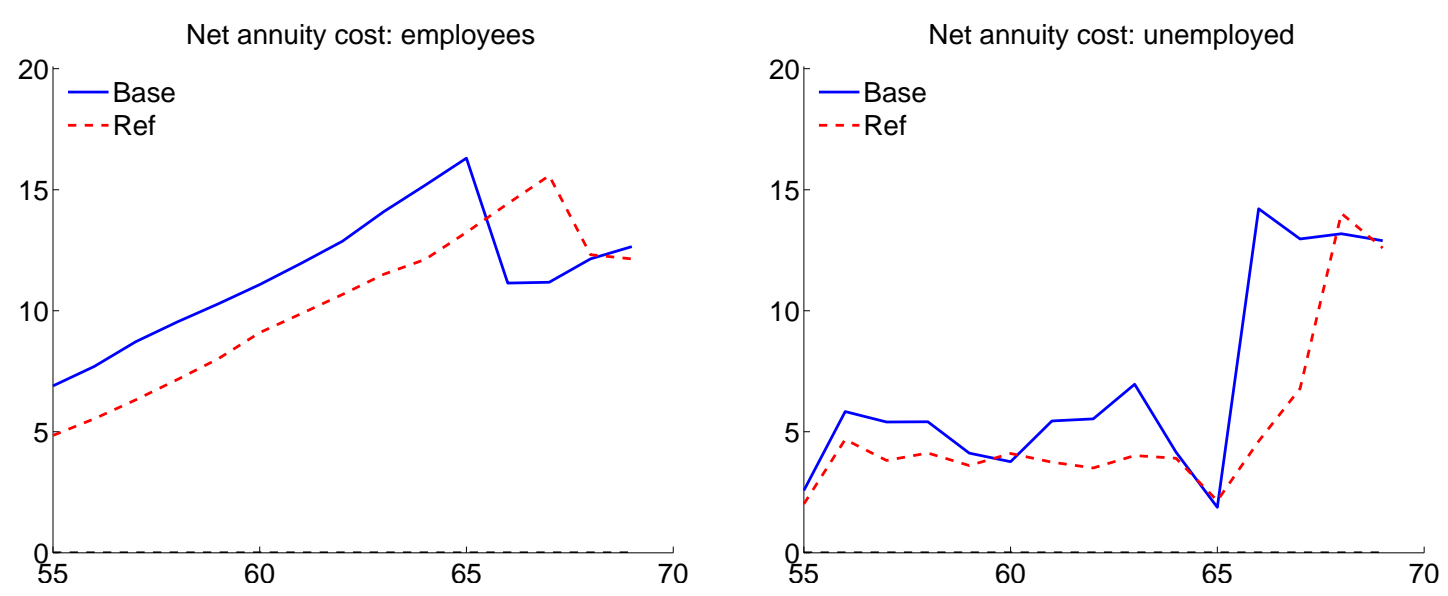

Figure 15: Average net annual cost of employees (left panel) and unemployed workers (right panel) in two institutional environments: the benchmark economy (blue continuous line) vs the pension reform economy (dashed, red line). All figures are in thousand of Euros of 2002.

\section{B Net pension/unemployment costs}

This appendix completes the information in the main text regarding the net costs (to the pension and unemployment system) of workers/unemployed with different characteristics. Figure 15 display the average net costs that employees and unemployed of different ages represent for the combined pension/unemployment protection system. It illustrates the differences resulting from the introduction of the pension reform (delay of the ERA to 63 and of the NRA to 67). The main text reproduces the differences in net pension costs in both systems (ie, the cost savings resulting from the reform).

The set of graphs in Figures 16 to 18 disaggregate the net pension cost by age according to the labor state/optimal choice of the considered individual. Note that in this set of graphs we represent one particular individual (previous wage and accrued pension rights of 16 thousand euros) rather than weighted values. Figure 16 display the structure observed in the benchmark economy, while Figures 17 and 18 illustrate the pension reform and voluntary ER environments.

\section{Robustness check: age-independent rate of arrival}

The process of arrival of job offers is a key input in our model of labor supply behavior of the unemployed. In this final section of the Appendix we test the robustness of our findings to the specification of this process. Specifically, we consider an alternative specification characterized by the absence of histeresis: all unemployed workers have the same probability of receiving a job offer, independently of the duration of the unemployment spell. Obviously, this specification does not perform as well as the one in the main text, but we can get a very reasonable adjustment if we simultaneously adjust the general rate of arrival of job offers. The alternative parameter 


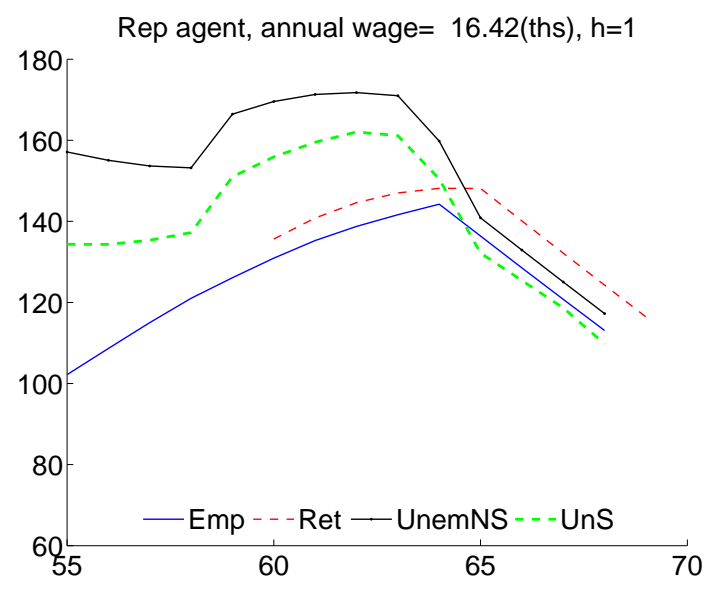

Figure 16: Base simulation: Net pension and unemployment costs for a representative individual in four labor states (employed (Emp), retired (Ret), unemployed without searching (UnemNS) and unemployed and searching (UnS).

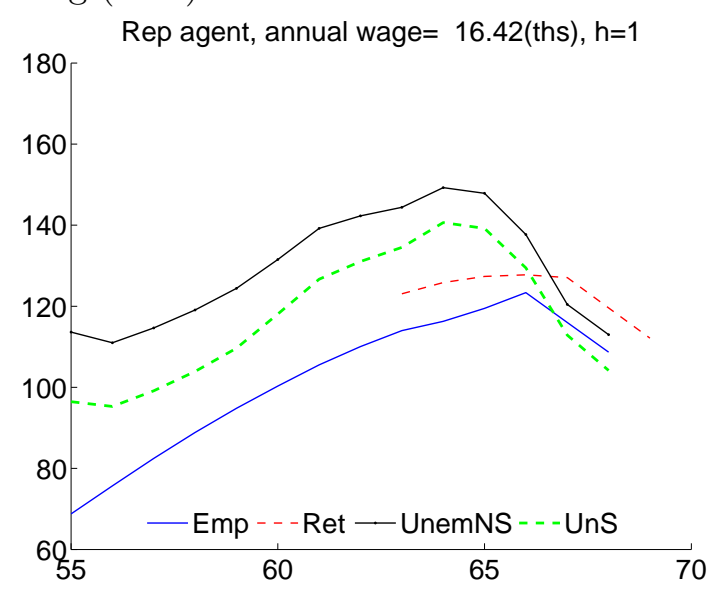

Figure 17: Pension reform simulation: Net pension and unemployment costs for a representative individual in four labor states

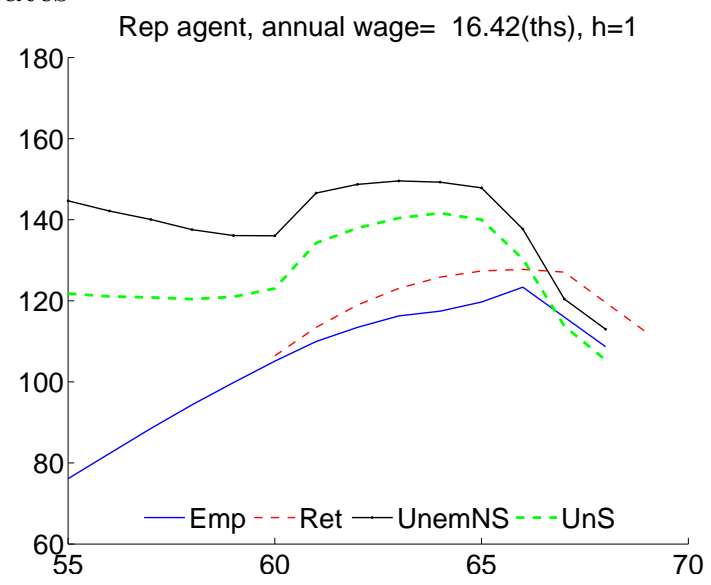

Figure 18: Voluntary ER simulation: Net pension and unemployment costs for a representative individual in four labor states 

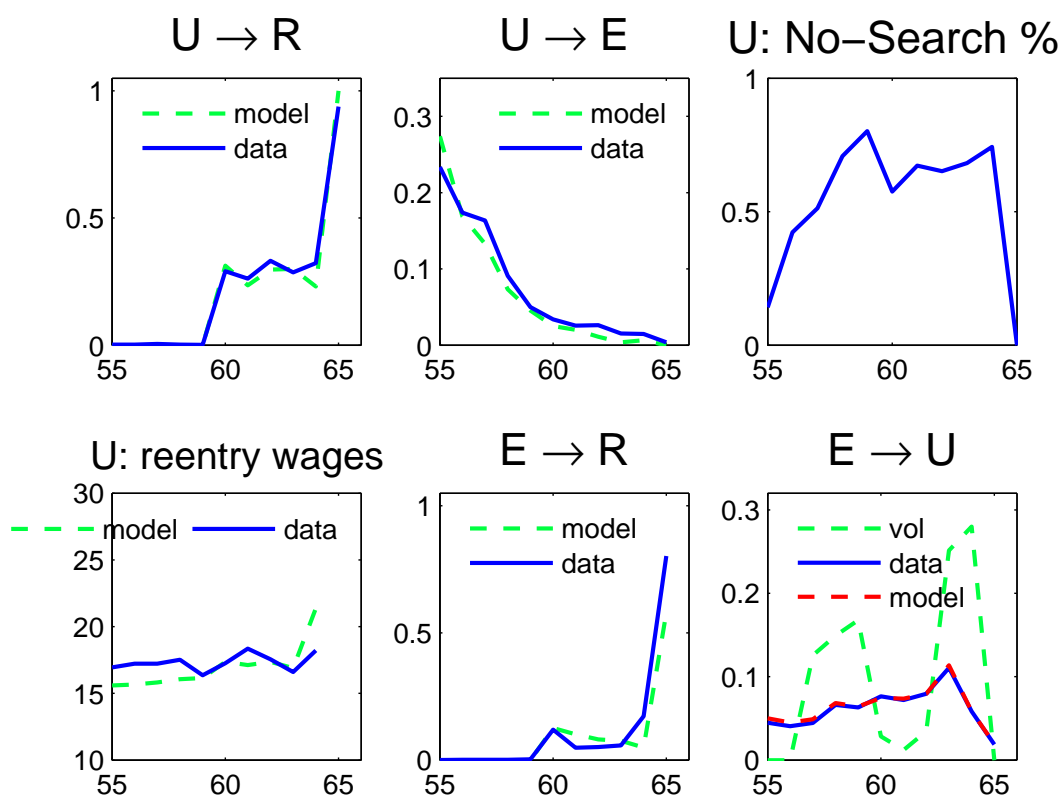

Figure 19: Sensitivity analysis: model performance vs empirical data in absence of histeresis

values selected for the simulation are $60 \%$ for workers with high pension rights and $40 \%$ for the rest (vs 80 and $65 \%$ in the main text). After the age of 60 , these rates still suffer a $30 \%$ drop (25\% in the main text). The resulting fit to the empirical data is shown in Figure 19. It is apparent that ability of the model to capture variation with age in the basic labor supply patterns is not a result of the assumed discrete drop in reemployment opportunities for the long term unemployed.

The main simulations results (cost savings and welfare impact of the reforms) in this alternative environment are presented in Table $6 .{ }^{30}$ Qualitatively, this table is almost indistinguishable from Table 4 in the main text. There are some quantitative differences, specially among the unemployed (the pension reform generates bigger savings in costs without imposing larger welfare costs and the voluntary ER reform fails to produce any extra cuts in costs). But we can clearly conclude that the main findings from our experiments are robust in this dimension.

\begin{tabular}{ccccccc}
\hline & \multicolumn{3}{c}{ Employees } & \multicolumn{3}{c}{ Unemployed } \\
& NAC & costs savings & welfare loss & NAC & costs savings & welfare loss \\
\hline Base & 168.03 & - & - & 202.27 & - & - \\
Pension Reform & 134.36 & 2.38 & 3.96 & 157.31 & 3.17 & 6.37 \\
Voluntary ER & 136.32 & 0.06 & -1.79 & 159.18 & 0.02 & -2.65 \\
\hline
\end{tabular}

Table 6: Net Aggregate pension-unemployment Cost and welfare impact in different institutional environments. All figures in thousand of euros of 2008.

\footnotetext{
${ }^{30}$ The labor impact of the reform is not reproduced to save space, but we also find very similar results in absence of histeresis to those in the main text.
} 